\title{
Label-free quantitative proteomic analysis of alfalfa in response to microRNA156 under high temperature
}

\author{
Muhammad Arshad ${ }^{1,2^{*}}$, Alpa Puri ${ }^{1,3}$, Aaron J. Simkovich ${ }^{1,3}$, Justin Renaud ${ }^{1}$, Margaret Y. Gruber ${ }^{4}$, \\ Frédéric Marsolais ${ }^{1,3}$ and Abdelali Hannoufa ${ }^{1,3^{*}}$ (D)
}

\begin{abstract}
Background: Abiotic stress, including heat, is one of the major factors that affect alfalfa growth and forage yield. The small RNA, microRNA156 (miR156), regulates multiple traits in alfalfa during abiotic stress. The aim of this study was to explore the role of miR156 in regulating heat response in alfalfa at the protein level.

Results: In this study, we compared an empty vector control and miR156 overexpressing (miR156OE) alfalfa plants after exposing them to heat stress $\left(40^{\circ} \mathrm{C}\right)$ for $24 \mathrm{~h}$. We measured physiological parameters of control and miR156OE plants under heat stress, and collected leaf samples for protein analysis. A higher proline and antioxidant contents were detected in miR1560E plants than in controls under heat stress. Protein samples were analyzed by label-free quantification proteomics. Across all samples, a total of 1878 protein groups were detected. Under heat stress, 45 protein groups in the empty vector plants were significantly altered $\left(P<0.05 ;\left|\log _{2} \mathrm{FC}\right|>2\right)$. Conversely, 105 protein groups were significantly altered when miR1560E alfalfa was subjected to heat stress, of which 91 were unique to miR156OE plants. The identified protein groups unique to miR156OE plants were related to diverse functions including metabolism, photosynthesis, stress-response and plant defenses. Furthermore, we identified transcription factors in miR156OE plants, which belonged to squamosa promoter binding-like protein, MYB, ethylene responsive factors, AP2 domain, ABA response element binding factor and bZIP families of transcription factors.
\end{abstract}

Conclusions: These results suggest a positive role for miR156 in heat stress response in alfalfa. They reveal a miR156-regulated network of mechanisms at the protein level to modulate heat responses in alfalfa.

Keywords: Alfalfa, Heat stress, miR156, Proteomic, LC-MS/MS

\section{Background}

Alfalfa (Medicago sativa L.) is an important leguminous crop that is grown worldwide as forage for livestock feed, and contributes to improved soil quality. Another important feature of this crop is the potential for multiple harvests throughout the growing season, allowing for abundant biomass yield. Perennial nature of alfalfa

\footnotetext{
*Correspondence: ma5877@nyu.edu; Abdelali.Hannoufa@canada.ca ${ }^{1}$ Agriculture and Agri-Food Canada, 1391 Sandford Street, London, Ontario N5V 4T3, Canada

Full list of author information is available at the end of the article
}

and its rapid biomass production make it a suitable source for bioenergy purpose. However, these benefits are offset by alfalfa's susceptibility to environmental stresses including heat, which exerts adverse effects on its growth and productivity [1]. High temperature can negatively affect plant growth and development including reduced seed germination [2], damage to leaves and branches, increase in leaf senescence, discoloring of fruits, which ultimately leads to poor crop yield [3]. Climate models have predicted an increase in seasonal temperatures globally, which may have a negative impact on

(c) The Author(s). 2020 Open Access This article is licensed under a Creative Commons Attribution 4.0 International License, which permits use, sharing, adaptation, distribution and reproduction in any medium or format, as long as you give appropriate credit to the original author(s) and the source, provide a link to the Creative Commons licence, and indicate if changes were made. The images or other third party material in this article are included in the article's Creative Commons licence, unless indicated otherwise in a credit line to the material. If material is not included in the article's Creative Commons licence and your intended use is not permitted by statutory regulation or exceeds the permitted use, you will need to obtain permission directly from the copyright holder. To view a copy of this licence, visit http://creativecommons.org/licenses/by/4.0/ The Creative Commons Public Domain Dedication waiver (http://creativecommons.org/publicdomain/zero/1.0/) applies to the data made available in this article, unless otherwise stated in a credit line to the data. 
crop growth, productivity and ultimately food security [4]. Developing alfalfa cultivars with improved heat stress tolerance could provide a sustainable solution to the unpredictable changes in the environmental conditions.

Molecular approaches have widely been used for dissecting the underlying biological and cellular processes under abiotic stress in plants [5-8]. Proteomic approaches have increasingly been used in plant research, and in particular to study abiotic stress responses as changes in protein abundance play a vital role in stress tolerance [9-12]. Proteomic analysis is a powerful technique to study gene products (proteins) at the molecular level $[13,14]$, and these have been used to study the underlying molecular and physiological processes for heat stress tolerance in different plant species. For example, a proteomic study showed that abundance of heat shock proteins (HSPs) and antioxidant enzymes were increased in heat-stressed leaves of rice [15]. Moreover, a heat stress-induced abundance of various protein groups involved in protein biosynthesis, degradation, and carbohydrate metabolism was reported in rice [16]. A similar study in grapevine showed that the abundance of HSPs and proteins involved in metabolism and signal transduction was significantly altered under heat stress [17]. Similarly, another study reported the differential abundance of 81 protein groups under heat stress in alfalfa. These proteins belonged to important functional categories such as metabolism, energy, protein synthesis, signal transduction and defense [6].

The microRNAs (miRNAs) are key regulators of gene expression at both the transcriptional and posttranscriptional levels $[18,19]$. These miRNAs are approximately 18-24 nt long and are grouped based on the differences in their biogenesis and functional characteristics [20]. Recently, microRNA156 (miR156) has emerged as an effective molecular tool for trait improvement in different plant species including alfalfa. For example, miR156 overexpression increased alfalfa biomass and delayed flowering [21, 22]. Moreover, transcriptome analysis of miR156 overexpressing (miR156OE) alfalfa under drought revealed potential miR156 targets, and subsequent characterization confirmed its role in drought tolerance [23]. Major transcription factors regulated by miR156 belong to Squamosa Promoter Binding Protein-Like (SPL) family [24]. Previously, we identified miR156 target SPL genes, and characterized their functions in alfalfa, including their role in drought and salinity responses [25-27]. Despite a series of miR156-related studies in different plant species, there has been no reported proteome analysis on miR156OE alfalfa under heat stress. Proteome analysis of contrasting alfalfa genotypes under heat stress conditions could provide an insight into the underlying molecular mechanisms that control different physiological and molecular traits in alfalfa.
Accumulation of osmoprotectants, such as proline, is an important physiological mechanism that helps plants scavenge reactive oxygen species (ROS) to cope with heat-related oxidative stress $[28,29]$. Proline helps plants keep a fully functional photosynthetic apparatus by stabilizing the photosynthetic complex II as well as membrane proteins such as rubisco [30]. Studies have shown that proline accumulation improves heat stress tolerance in a range of plant species such as tomato [31], rice [32], chickpea [33] and barley [34].

Recently, our group has shown that miR156 overexpression resulted in an improved physiological response of alfalfa to heat stress [35]. This finding triggered our interest in expanding our research to dissect the role of miR156 in modulating the proteome of alfalfa in response to heat. We employed a label-free quantification (LFQ) based quantitative proteomics approach to explore the effects of heat stress on protein levels in miR156OE alfalfa. Our major objective was to identify miR156-regulated gene products with differentially altered abundance under heat stress. In the current study, miR156OE plants showed enhanced levels of stress tolerance predictors (antioxidants and proline) under heat stress. Moreover, this study revealed that metabolism, photosynthesis and defense were the major processes affected by miR156 under heat. This combination of biochemical and proteomic analyses with miR156 influence provided additional knowledge of heat tolerance mechanisms, thereby shedding a light on the pathways mediated by miR156 for heat stress response in alfalfa.

\section{Results}

Findings from our previous study that miR156 modulated heat stress response in alfalfa [35], prompted us to further study the molecular mechanism for regulation of heat stress tolerance. We conducted this research with an aim to identify proteins with differentially altered abundance modulated by miR156 under high temperature.

\section{Biochemical characterization of miR1560E alfalfa}

Plants produce free radicals in response to stress, and these can be harmful to cellular membrane and lipids. To counter the negative effect of these free radicals, plants synthesize antioxidants as a defense mechanism, which prevent cellular damage by quenching free radicals [36]. To explore whether miR156 alters the ability of alfalfa to produce antioxidants for defense, we determined total antioxidant contents in EV and A8 under non-stressed control and heat stress conditions. Overall, A8 showed a mild increase in antioxidant content under non-stress control and stress conditions compared to EV (Fig. 1a). 


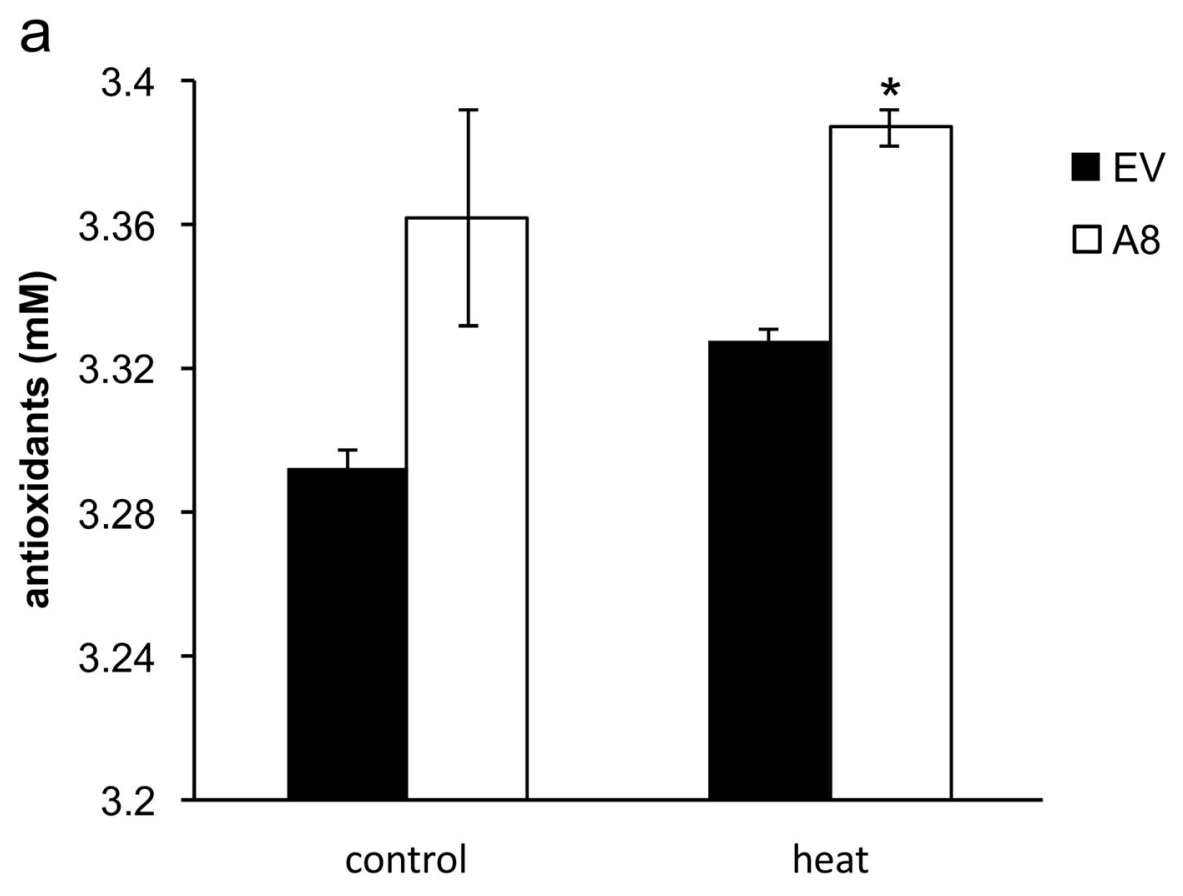

b

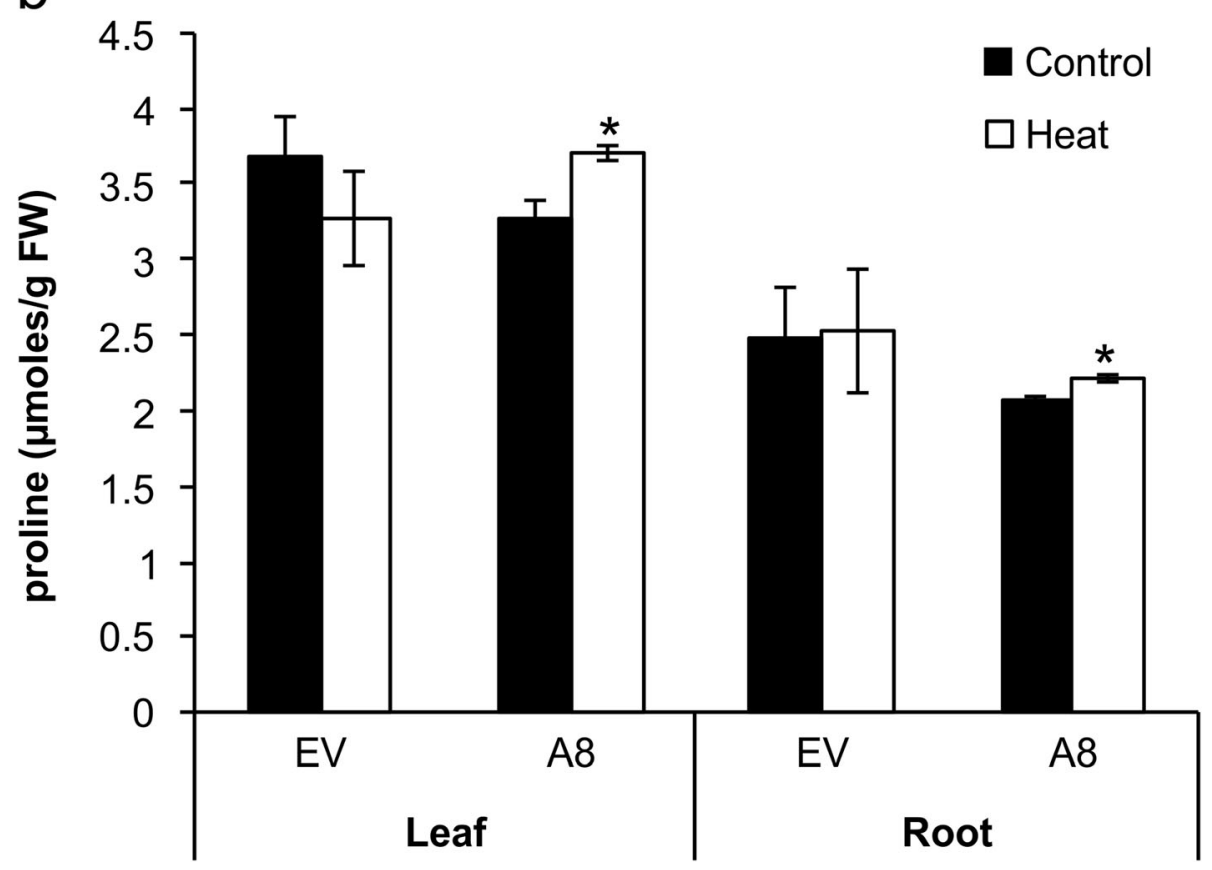

Fig. 1 MiR156 alters the physiological responses of alfalfa to heat stress. Levels of $\mathbf{a}$ antioxidants, and $\mathbf{b}$ proline in EV control and A8. Asterisk (*) shows statistical significance at $p<0.05$ where $n=3-4$ (t-test)

As a defence mechanism, plants synthesize an array of metabolites under stress conditions including amino acids such as proline. Proline is a compatible solute that can help plants to increase water uptake from soil. Higher levels of proline are beneficial for plants under abiotic stress conditions [36]. In the current study, no significant difference in proline accumulation was observed between non-stressed and stressed plants for the EV control in either leaf or root (Fig. 1b). On the other hand, a significant increase in proline accumulation was 
detected in both heat-stressed leaf and root of A8 compared to corresponding non-stressed control plants (Fig. 1b).

\section{Alfalfa proteome is affected by miR156 under heat stress} Previously, our group showed that overexpression of miR156 improved multiple physiological traits and altered the transcriptome profile of alfalfa [37]. Further investigations revealed a positive role for miR156 in abiotic stress tolerance, including drought [26, 38], salinity [27] and heat [35]. In addition, transcriptomic analysis showed that miR156 affects a wide array of gene families under drought stress in alfalfa [23]. We, therefore, set out to identify miR156-regulated gene products (proteins) with differentially altered abundance under heat stress in alfalfa. Across all samples, a total of 1878 protein groups were detected (online repository). To assess the effect of heat on the protein profile, protein abundance was compared between non-stressed control and heat-stressed plants of EV and A8. Results illustrated that the abundance of 12 proteins was significantly increased $(P<0.05 ; \log 2 \mathrm{FC}>1)$, and that of 33 proteins was significantly decreased $(\mathrm{P}<0.05$; $\log 2 \mathrm{FC}<-1$ ), in EV under heat stress relative to the corresponding non-stressed plants (Fig. 2a, b; Table 1). On the other hand, almost six-fold number of proteins (73) showed significantly enhanced abundance, and 32 proteins showed reduced abundance in A8 under heat stress relative to the corresponding A8 non-stressed plants (Fig. 2a, b; Table 2). While a small number of the differentially altered proteins (14) were common to both genotypes, a total of 91 proteins exhibited differential abundance uniquely in A8 under heat stress (68 proteins increased; 23 proteins reduced) (Fig. 2; Tables 1 and 2).

The abundance of some proteins belonging to heat shock family was altered in both EV and A8 genotypes. Glutamine synthetase, fructose-bisphosphate aldolase (FBA), photosystem II proteins and Glucose-6phosphate 1-dehydrogenase (G-6-PDH), Calnexin, lethal leaf-spot protein, $\alpha$-galactosidase, $\beta$-galactosidase and Chitinase were among the major protein groups with

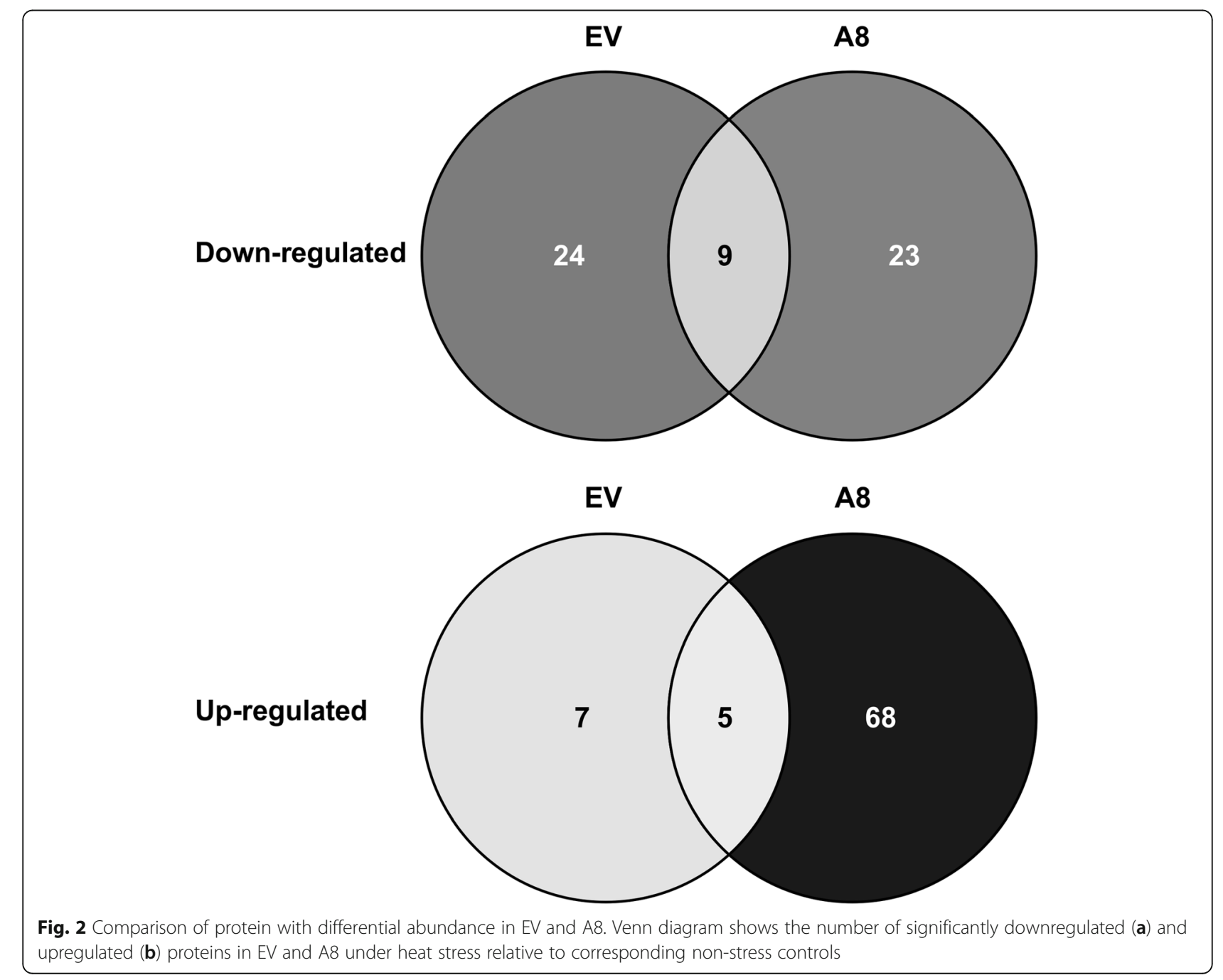


Table 1 Identified proteins with differentially altered abundance in EV controls under heat stress relative to the non-stress EV control plants

\begin{tabular}{|c|c|c|c|c|}
\hline Protein ID & Locus name & Log2 (fold change) & FDR & annotation \\
\hline G7JFK1 & MTR_4g130540 & -7.83 & 0.0161 & Heat shock $70 \mathrm{kDa}$ protein \\
\hline Q2HTU2 & MTR_4g091590 & -7.00 & 0.0191 & 17.6 kDa class I heat shock protein \\
\hline A0A072TL89 & MTR_0004s051 & -5.80 & 0.0035 & Putative small heat shock protein HSP2O \\
\hline A0A072UP91 & MTR_4g084250 & -4.83 & 0.0191 & Calcyclin-binding protein \\
\hline G7LF61 & MTR_8g012340 & -4.56 & 0.0275 & Peptidylprolyl isomerase \\
\hline G7L491 & MTR_7g012820 & -4.37 & 0.0191 & Casein lytic proteinase B3 \\
\hline G7KD12 & MTR_5g090410 & -4.14 & 0.0002 & Oxygen-evolving enhancer protein 2-1 \\
\hline G7KG40 & MTR_5g078040 & -3.56 & 0.0375 & Peroxisomal small heat shock protein \\
\hline G7L1Y9 & MTR_7g010800 & -3.45 & 0.0161 & ATP-dependent zinc metalloprotease FTSH protein \\
\hline G7KNT7 & MTR_6g061940 & -3.28 & 0.0436 & 17.6 kDa class I heat shock protein \\
\hline G7J8C7 & MTR_3g104780 & -3.23 & 0.0462 & 17.1 kDa class II heat shock protein \\
\hline G7K4W1 & MTR_5g096970 & -3.13 & 0.0035 & Carboxy-terminal TIM barrel domain enolase \\
\hline G7JMP4 & MTR_4g104300 & -3.10 & 0.0345 & F-box/RNI/FBD-like domain protein \\
\hline G7IRL3 & MTR_2g089340 & -2.95 & 0.0127 & Dihydroxyacid dehydratase \\
\hline G7KG90 & MTR_5g012030 & -2.86 & 0.0127 & Putative Heat shock chaperonin-binding \\
\hline A0A072VBG9 & MTR_2g084715 & -2.84 & 0.0018 & Putative transcription factor $\mathrm{C} 3 \mathrm{H}$ family \\
\hline G7L4S2 & MTR_7g088490 & -2.77 & 0.0327 & Proteasome subunit beta \\
\hline A0A072UGC6 & MTR_5g073235 & -2.50 & 0.0190 & Uncharacterized protein \\
\hline G7KGT1 & MTR_5g080450 & -2.32 & 0.0115 & Ribulose bisphosphate carboxylase/oxygenase activase \\
\hline G7KW94 & MTR_7g093500 & -2.30 & 0.0277 & Activator of $90 \mathrm{kDa}$ heat shock ATPase-like protein \\
\hline G7JL07 & MTR_4g072110 & -2.19 & 0.0191 & Amidophosphoribosyltransferase \\
\hline B7FLU4 & MTR_4g103790 & -1.99 & 0.0375 & NOP56-like pre RNA processing ribonucleoprotein \\
\hline A0A072TVH5 & MTR_0009s039 & -1.95 & 0.0434 & Heat shock protein $81-2$ \\
\hline G7KWU8 & MTR_7g024390 & -1.93 & 0.0126 & Heat shock cognate $70 \mathrm{kDa}$ protein \\
\hline A0A072UQ41 & MTR_4g105490 & -1.60 & 0.0375 & Synaptobrevin-like protein \\
\hline G7J3Q2 & MTR_3g087030 & -1.50 & 0.0478 & Molecular chaperone Hsp40/DnaJ family protein \\
\hline G7KEN6 & MTR_5g097320 & -1.50 & 0.0115 & Heat shock protein $81-2$ \\
\hline G7JNG4 & MTR_4g074480 & -1.49 & 0.0399 & Anamorsin homolog \\
\hline G7IHD7 & MTR_2g082590 & -1.46 & 0.0345 & Thioredoxin \\
\hline B7FKA1 & MTR_4g021570 & -1.43 & 0.0191 & Armadillo/beta-catenin-like repeat protein \\
\hline A0A072VEG8 & MTR_1g017380 & -1.28 & 0.0035 & Putative chaperonin Cpn60/TCP-1 family \\
\hline G719Z6 & MTR_1g031650 & -1.26 & 0.0191 & Calcium-dependent lipid-binding (CaLB domain) family \\
\hline A0A072UL44 & MTR_4g063710 & -1.23 & 0.0044 & Heat shock cognate $70 \mathrm{kDa}$ protein \\
\hline G716D7 & MTR_1g011800 & 1.07 & 0.0184 & Plant/F18G18-200 protein \\
\hline A0A072TUF8 & MTR_8g090025 & 1.55 & 0.0269 & Haloacid dehalogenase-like hydrolase \\
\hline G7ICF3 & MTR_1g018510 & 2.52 & 0.0184 & Subtilisin-like serine protease \\
\hline G7ILM0 & MTR_2g017730 & 2.52 & 0.0393 & Heat shock $70 \mathrm{kDa}$ protein \\
\hline A0A072UMH4 & MTR_4g066170 & 2.55 & 0.0191 & Lipoxygenase \\
\hline G7JCT4 & MTR_4g095360 & 2.79 & 0.0351 & Putative tripeptidyl-peptidase II \\
\hline A0A072VFH5 & MTR_2g023540 & 2.98 & 0.0253 & 5-adenylylsulfate reductase \\
\hline G7IAX3 & MTR_1g116270 & 3.19 & 0.0359 & Glutathione S-transferase \\
\hline A0A072UZV5 & MTR_3g078633 & 3.63 & 0.0191 & Enhanced disease susceptibility protein \\
\hline A0A072U496 & MTR_7g113480 & 4.25 & 0.0044 & Xaa-pro aminopeptidase $\mathrm{P}$ \\
\hline
\end{tabular}


Table 1 Identified proteins with differentially altered abundance in EV controls under heat stress relative to the non-stress EV control plants (Continued)

\begin{tabular}{lllll}
\hline Protein ID & Locus name & Log2 (fold change) & FDR & annotation \\
\hline G7J6G6 & MTR_3g116110 & 4.34 & 0.0184 & Photosystem II reaction center PsbP family protein \\
B7FKA0 & MTR_5g035010 & 4.62 & 0.0115 & Polyketide cyclase/dehydrase and lipid transporter \\
\hline
\end{tabular}

known functions in plant stress response, and their abundance was differentially altered in A8 under heat stress (Table 2). These protein groups with altered abundance uniquely in miR156OE plants under heat stress (Table 2) could be potentially regulated by miR156 specifically under stress conditions.

\section{Gene ontology (GO) enrichment analysis}

Gene ontology enrichment analysis was performed to identify pathways that may be affected in miR156OE plants under heat stress. We observed a large difference in $\mathrm{GO}$ function category representation between EV and miR156 genotypes. There were 76 GO terms that were assigned to protein with altered abundance in EV under stress, of which about half (49\%) were represented by proteins belonging to the cellular component category (Fig. 3a). Only four, six and five GO functional categories were detected in the biological process, cellular component and molecular function categories, respectively. Biological process included response to heat, protein folding, response to stimulus and seed germination (Fig. 3b). Plastid, external encapsulating structure, cell, catalytic complex, organelle and extrinsic component of membrane were present in the cellular component category (Fig. 3c). Moreover, ATP binding, unfolded protein binding, enzyme activator activity, hydrolase activity and endopeptidase activity represented the molecular function category (Fig. 3d).

On the other hand, $227 \mathrm{GO}$ terms were assigned to proteins with altered abundance in miR156 overexpressing genotype A8, of which a larger portion was represented by biological process (Fig. 4a). Many of these GO terms may reflect traits that miR156 overexpression modulates under stress conditions. Of the $21 \mathrm{GO}$ terms in the biological process; response to temperature stimulus, single-organism carbohydrate metabolism, plastid organization and coenzyme metabolism (Fig. 4b) were unique to miR156 overexpression and may be of particular interest for stress response. The function chloroplast made up one of the largest portions in the cellular component category (Fig. 4c). In addition, extracellular region and apoplast were also represented by this category (Fig. 4c). Among the 11 functions classified as molecular function; purine ribonucleoside triphosphate binding, catalytic activity and fructose-bisphosphate adolase activity (Fig. 4d) were the main terms unique to miR156.

\section{Transcription factor enrichment}

Transcription factor (TF) enrichment analysis was carried out for the 91 proteins unique to miR156 to explore the functional mechanism of miR156 transcriptional regulatory systems. A total of 37 TFs were predicted (Table 3) that may be affected by miR156 under heat stress conditions. Major transcription factor families included heat shock transcription factors, MYB transcription factors, ethylene responsive factor, TCP family transcription factor, squamosa promoter-binding-like protein (SPL), ABA response element-binding factor and bZIP transcription factor (Table 3).

\section{Discussion}

Current climate change models predict an increase in average surface temperatures of $3^{\circ} \mathrm{C}$ to $5^{\circ} \mathrm{C}$ in the next 5 to 10 decades. This may have deleterious effects on crop plant growth and productivity [39]. High temperature can cause devastating effects on various aspects of plant function and physiology as well as disruption of cellular homeostasis [40]. Our group has recently shown that heat stress exerted negative impact on alfalfa plants where EV control leaves looked droopy and brownish whereas miR156 overexpression plants (miR156OE) including A8 maintained green and normal phenotype [35]. Moreover, miR156OE plants showed increased accumulation of antioxidants and water potential under heat stress compared to control plants. These results provided evidence that overexpression of miR156 enhances alfalfa tolerance to heat stress [35].

In the current study, MaxLFQ algorithm was used to assemble protein abundance profiles with maximum possible information from MS signals [41]. Heat stress response of miR156OE alfalfa was compared with that of the empty vector EV control genotype in an attempt to identify heat stress-related proteins regulated by miR156, as well as to further elucidate the biochemical and molecular mechanisms of heat tolerance in alfalfa, which are discussed below.

Physiological response of miR1560E alfalfa to heat stress High temperature can cause an array of physiological and biochemical changes in plants that adversely affect growth, development, and yield [40]. Plants have, however, evolved mechanisms to cope with environmental stressors. In response to heat stress, plants produce reactive oxygen species (ROS), which can serve as stress 
Table 2 Identified proteins with differentially altered abundance in miR156 overexpressing genotype (A8) under heat stress relative to the non-stress control A8 plants

\begin{tabular}{|c|c|c|c|c|}
\hline Protein IDs & Locus name & Log2 (fold change) & FDR & annotation \\
\hline aG7JFK1 & MTR_4g130540 & -7.85 & 0.0064 & Heat shock $70 \mathrm{kDa}$ protein \\
\hline A0A072U9J1 & MTR_6g452990 & -6.82 & 0.0080 & Heat shock protein $81-2$ \\
\hline${ }^{\mathrm{a} A 0 A 072 T L 89}$ & MTR_0004s051 & -6.52 & 0.0207 & Putative small heat shock protein HSP20 \\
\hline${ }^{\mathrm{a} G 7 K G 40}$ & MTR_5g078040 & -4.57 & 0.0050 & Peroxisomal small heat shock protein \\
\hline G7JGX6 & MTR_4g010130 & -4.40 & 0.0157 & Sterol regulatory element-binding protein \\
\hline G7IF74 & MTR_1g088640 & -4.31 & 0.0048 & Putative universal stress protein A \\
\hline${ }^{\mathrm{a} G 7 \mid R L 3}$ & MTR_2g089340 & -3.60 & 0.0076 & Dihydroxyacid dehydratase \\
\hline G7LGJ8 & MTR_8g095680 & -3.33 & 0.0173 & Calnexin 2 \\
\hline${ }^{\mathrm{a} G 7 K W U 8}$ & MTR_7g024390 & -3.24 & 0.0160 & Heat shock cognate $70 \mathrm{kDa}$ protein \\
\hline${ }^{\mathrm{a} G} \mathrm{G} L 491$ & MTR_7g012820 & -2.70 & 0.0080 & Casein lytic proteinase B3 \\
\hline G7K8X5 & MTR_5g059210 & -2.63 & 0.0340 & Ubiquitin-fold modifier 1 \\
\hline G7JM88 & MTR_4g057200 & -2.54 & 0.0048 & Lethal leaf-spot protein, putative \\
\hline G7K9T0 & MTR_5g038460 & -2.41 & 0.0204 & Plant/T7N9-9 protein \\
\hline A0A072UC14 & MTR_7g077400 & -2.29 & 0.0058 & Acyl-CoA thioesterase \\
\hline G7JI82 & MTR_3g082660 & -2.06 & 0.0076 & Bacterial long-chain fatty acid CoA synthetase \\
\hline${ }^{\mathrm{a} G 7 K E N 6}$ & MTR_5g097320 & -1.89 & 0.0258 & Heat shock protein $81-2$ \\
\hline G7IQD5 & MTR_2g045050 & -1.86 & 0.0209 & Acyl-CoA thioesterase \\
\hline G7L9N5 & MTR_8g089560 & -1.76 & 0.0380 & Putative RIN4, pathogenic type III effector \\
\hline A2Q5W0 & MTR_7g085800 & -1.68 & 0.0422 & Tubulin alpha chain \\
\hline${ }^{\mathrm{a} B 7 F K A 1}$ & MTR_4g021570 & -1.58 & 0.0350 & Armadillo/beta-catenin-like repeat protein \\
\hline G7JNV8 & MTR_4g106880 & -1.55 & 0.0069 & Peroxisomal membrane PEX14-like protein \\
\hline G7IMW8 & MTR_2g034900 & -1.51 & 0.0076 & Importin subunit alpha \\
\hline G7JNZ5 & MTR_4g122670 & -1.38 & 0.0105 & Mevalonate/galactokinase family protein \\
\hline aA0A072UL44 & MTR_4g063710 & -1.29 & 0.0173 & Heat shock cognate 70 kDa protein \\
\hline G7L8K5 & MTR_8g046300 & -1.20 & 0.0258 & Prohibitin \\
\hline G7JRF5 & MTR_4g036260 & -1.19 & 0.0202 & Quinone-oxidoreductase-like protein \\
\hline G7K595 & MTR_5g016590 & -1.18 & 0.0301 & Proteasome subunit alpha type \\
\hline A0A072TUS4 & MTR_8g099795 & -1.16 & 0.0292 & Heat shock $70 \mathrm{kDa}$ protein \\
\hline G717Q4 & MTR_1g025430 & -1.15 & 0.0173 & Heat shock protein $81-2$ \\
\hline G71836 & MTR_1g082870 & -1.10 & 0.0173 & Mitochondrial Rho GTPase \\
\hline G7LIP6 & MTR_8g086070 & -1.03 & 0.0341 & Dicarboxylate carrier protein \\
\hline A0A072VXV5 & MTR_1g077480 & -1.00 & 0.0392 & Alpha-galactosidase \\
\hline G7KUS5 & MTR_7g022440 & 1.03 & 0.0329 & Glucose-6-phosphate 1-dehydrogenase \\
\hline G7JW95 & MTR_5g022300 & 1.07 & 0.0155 & Ferredoxin--NADP reductase, chloroplastic \\
\hline B7FJJ4 & MTR_7g005380 & 1.12 & 0.0269 & Pyruvate dehydrogenase E1 component subunit \\
\hline G7JAPO & MTR_3g070100 & 1.15 & 0.0337 & Putative sedoheptulose-bisphosphatase \\
\hline G7JI05 & MTR_4g131760 & 1.28 & 0.0096 & Glucose-1-phosphate adenylyltransferase \\
\hline Q45FF2 & MTR_2g017520 & 1.29 & 0.0080 & Q45FF2_MEDTR Pyridoxal 5-phosphate synthase \\
\hline A2Q5N9 & MTR_7g085490 & 1.29 & 0.0155 & Galactose mutarotase-like \\
\hline G7IBQ7 & MTR_1g086050 & 1.31 & 0.0429 & Protein translocase subunit SecA \\
\hline G7K882 & MTR_5g027530 & 1.31 & 0.0080 & Phosphoribulokinase \\
\hline Q84UC1 & MTR_2g021255 & 1.32 & 0.0274 & Glutamine synthetase \\
\hline A0A072V8Q4 & MTR_2g046710 & 1.32 & 0.0144 & S-adenosylmethionine synthase \\
\hline
\end{tabular}


Table 2 Identified proteins with differentially altered abundance in miR156 overexpressing genotype (A8) under heat stress relative to the non-stress control A8 plants (Continued)

\begin{tabular}{|c|c|c|c|c|}
\hline Protein IDs & Locus name & Log2 (fold change) & FDR & annotation \\
\hline G7IED1 & MTR_1g072260 & 1.36 & 0.0221 & Putative NAD(P)-binding domain-containing \\
\hline A0A072UUQ2 & MTR_4g045980 & 1.39 & 0.0173 & Photosystem II biogenesis protein \\
\hline A0A072ULBO & MTR_4g071880 & 1.39 & 0.0203 & Fructose-bisphosphate aldolase \\
\hline A0A072UDY2 & MTR_5g004680 & 1.40 & 0.0173 & Presequence protease \\
\hline A0A072VPY5 & MTR_1g023120 & 1.41 & 0.0389 & Beta-galactosidase \\
\hline A0A072V4D0 & MTR_3g112420 & 1.42 & 0.0392 & ATP-dependent protease LA (Lon) domain protein \\
\hline G7J8Z9 & MTR_3g092720 & 1.44 & 0.0329 & Putative ribosomal protein S30Ae/sigma \\
\hline G7L028 & MTR_7g026340 & 1.46 & 0.0114 & Glucan endo-1,3-beta-glucosidase-like protein \\
\hline A0A072VMHO & MTR_1g076570 & 1.47 & 0.0173 & 2-methyl-6-phytylbenzoquinone methyltransferase \\
\hline A0A072V2V0 & MTR_3g498725 & 1.49 & 0.0185 & ATP-dependent Clp protease ATP-binding subunit \\
\hline A0A072U1Q8 & MTR_7g066120 & 1.54 & 0.0188 & Fructose-1,6-bisphosphatase \\
\hline A0A072TGRO & MTR_0151s003 & 1.55 & 0.0444 & Inositol-1-monophosphatase \\
\hline A9YWSO & MTR_5g030950 & 1.56 & 0.0294 & Serine hydroxymethyltransferase \\
\hline I3S8V0 & MTR_7g111860 & 1.57 & 0.0050 & Putative NAD(P)-binding domain-containing protein \\
\hline G7LJD5 & MTR_8g070530 & 1.62 & 0.0105 & Phototropin-2 protein \\
\hline G7LE33 & MTR_8g093770 & 1.65 & 0.0105 & $40 \mathrm{~S}$ ribosomal protein S12 \\
\hline A0A072UYT5 & MTR_3g068030 & 1.68 & 0.0202 & Ribulose bisphosphate carboxylase/oxygenase activase \\
\hline G7LIX6 & MTR_8g018510 & 1.69 & 0.0086 & Lipoxygenase \\
\hline A0A072TX52 & MTR_8g012565 & 1.73 & 0.0050 & 1-deoxy-D-xylulose 5-phosphate reductoisomerase \\
\hline${ }^{\mathrm{a} G 7 J C T 4}$ & MTR_4g095360 & 1.76 & 0.0130 & Putative tripeptidyl-peptidase ॥ \\
\hline G7L4Q1 & MTR_7g077880 & 1.76 & 0.0258 & Putative HAD-like domain-containing protein \\
\hline G7K1Y1 & MTR_5g079460 & 1.80 & 0.0173 & PfkB family carbohydrate kinase \\
\hline G7KG86 & MTR_5g011990 & 1.82 & 0.0155 & Uncharacterized protein \\
\hline G7KET9 & MTR_5g011220 & 1.84 & 0.0080 & PGR5-like protein 1A \\
\hline G712N9 & MTR_1g073130 & 1.85 & 0.0479 & Carboxy-terminal processing peptidase-like protein \\
\hline G7K4T4 & MTR_5g096670 & 1.87 & 0.0258 & Fructose-bisphosphate aldolase \\
\hline G7LA76 & MTR_8g074330 & 1.88 & 0.0130 & Chitinase (Class lb) / Hevein \\
\hline A0A072VNF5 & MTR_1g096240 & 1.90 & 0.0405 & Dihydrolipoamide acetyltransferase \\
\hline A0A072UL99 & MTR_4g071190 & 1.91 & 0.0202 & Uncharacterized protein \\
\hline G7JBK8 & MTR_3g096290 & 1.91 & 0.0317 & Cyanobacterial and plant NDH-1 subunit $\mathrm{O}$ \\
\hline G7K999 & MTR_5g009010 & 1.92 & 0.0117 & Putative THUMP domain-containing protein \\
\hline G7LH37 & MTR_8g083210 & 1.95 & 0.0302 & Aspartokinase-homoserine dehydrogenase \\
\hline A0A072TEN7 & MTR_0380s004 & 1.98 & 0.0173 & Putative nucleoid-associated protein YbaB/EbfC \\
\hline A0A072VAN9 & MTR_2g090200 & 1.99 & 0.0048 & Photosystem II Pbs27 protein \\
\hline A0A072VRL6 & MTR_1g107340 & 2.02 & 0.0156 & Limonoid UDP glucosyltransferase, putative \\
\hline A0A072UYV0 & MTR_4g088615 & 2.03 & 0.0076 & Putative ribosomal protein S5 \\
\hline I3SSE5 & MTR_8g005175 & 2.04 & 0.0072 & Oxygen-evolving enhancer protein \\
\hline G7JK55 & MTR_4g101750 & 2.06 & 0.0290 & Elongation factor $\mathrm{G}$, chloroplastic \\
\hline G7KDR6 & MTR_5g030020 & 2.09 & 0.0301 & Putative nucleotide-binding alpha-beta protein \\
\hline A0A072TTP2 & MTR_8g080230 & 2.12 & 0.0166 & Lipoxygenase \\
\hline A0A072TLC8 & MTR_0003s056 & 2.16 & 0.0340 & Carboxypeptidase \\
\hline G7JBQ7 & MTR_3g108040 & 2.19 & 0.0080 & PsbP domain protein \\
\hline G7JEX7 & MTR_4g068280 & 2.21 & 0.0048 & Putative trigger factor \\
\hline
\end{tabular}


Table 2 Identified proteins with differentially altered abundance in miR156 overexpressing genotype (A8) under heat stress relative to the non-stress control A8 plants (Continued)

\begin{tabular}{lllll}
\hline Protein IDs & Locus name & Log2 (fold change) & FDR & annotation \\
\hline G7JZK0 & MTR_5g071360 & 2.25 & 0.0173 & Asparagine synthetase [glutamine-hydrolyzing] \\
A0A072VDJ3 & MTR_2g105480 & 2.38 & 0.0130 & Putative ATPase, AAA-type, P-loop \\
A0A072UF41 & MTR_5g084030 & 2.39 & 0.0144 & Indole-3-glycerol phosphate synthase \\
G7JFL4 & MTR_4g130680 & 2.39 & 0.0329 & ATP phosphoribosyltransferase catalytic subunit \\
G7KEX7 & MTR_5g020640 & 2.47 & 0.0050 & Glucose-6-phosphate 1-epimerase \\
G7LAE7 & MTR_8g091410 & 2.51 & 0.0189 & Peptidylprolyl isomerase \\
aA0A072UMH4 & MTR_4g066170 & 2.53 & 0.0033 & Lipoxygenase \\
G7J557 & MTR_3g100500 & 2.70 & 0.0144 & Aspartic proteinase nepenthesin-like protein \\
G7KPU0 & MTR_6g088270 & 2.70 & 0.0207 & Elongation factor Ts, mitochondrial \\
G8A394 & MTR_3g073860 & 2.74 & 0.0290 & Acetyl-CoA carboxylase \\
A0A072U515 & MTR_7g117430 & 3.20 & 0.0064 & Eukaryotic aspartyl protease family protein \\
G7L4R0 & MTR_7g088340 & 3.23 & 0.0155 & Magnesium-protoporphyrin IX monomethyl ester \\
${ }^{a}$ A0A072U496 & MTR_7g113480 & 3.26 & 0.0050 & Xaa-pro aminopeptidase P \\
A0A072VID5 & MTR_1g052535 & 3.27 & 0.0270 & GTP-binding protein TypA/BipA \\
A0A072UMH6 & MTR_6g085010 & 3.55 & 0.0096 & Aspartic protease in GUARD CELL-like protein \\
aG7J6G6 & MTR_3g116110 & 3.98 & 0.0110 & Photosystem II reaction center PsbP family protein \\
G7LAD5 & MTR_8g091320 & 4.13 & 0.0050 & Myo-inositol 1-phosphate synthase \\
${ }^{2}$ B7FKA0 & MTR_5g035010 & 5.32 & 0.0080 & Polyketide cyclase/dehydrase and lipid transporter \\
A0A072VIV9 & MTR_1g052165 & 7.39 & 0.0219 & Esterase D, putative \\
\hline aPFeins hatwo &
\end{tabular}

${ }^{\mathrm{a}}$ Proteins that were common to A8 and EV genotypes under heat shock. All other proteins were unique to A8

FDR False discovery rate

signals to trigger defense responses; at the same time, ROS can cause cellular damage [42]. To neutralize ROS, plants synthesize antioxidants that protect the cellular machinery by scavenging ROS [36]. Enhanced accumulation of antioxidants positively correlates with stress tolerance in several plant species [26, 27, 36]. Previously, our group showed that miR156OE alfalfa accumulated increased levels of antioxidants under drought and saline conditions, and the plants exhibited resilience to these stresses [26, 27]. In the current study, the miR156OE plants exhibited improved antioxidant capacity, which may suggest that miR156 can exert a defense response against ROS under heat stress conditions, and this could potentially improve heat stress tolerance in alfalfa.

Elevated proline levels help plants cope with stress, and accumulation of proline indicates improved cellular metabolism and enzymatic activity [43]. In line with the previous study that was conducted on non-transgenic control alfalfa plants [5], our results showed a mild increase in proline accumulation in leaf and root of miR156OE alfalfa, suggesting that miR156 may regulate the biosynthesis of this osmolyte in response to heat stress. In addition to affecting heat stress responses, we previously showed that genotype A8 accumulated higher proline and had elevated relative water content (RWC) under drought stress, and this genotype also displayed improved tolerance under this stress [26]. Together, these results support our current results that miR156 modulates a wide variety of abiotic stresses including heat $[25-27,44]$. Increased proline accumulation correlates with higher RWC. A wheat genotype sensitive to drought exhibited reduced RWC at $30 \%$ of soil moisture, whereas RWC was not reduced in a drought tolerant genotype [45]. Similarly, a reduction in leaf water potential, stomatal conductance and transpiration rate, and an increase in leaf temperature and abscisic acid (ABA) level were observed in two genotypes of soybean under heat stress [46]. ABA is a stress hormone that triggers proline synthesis and helps plants combat stress conditions by altering physiological and molecular responses [47]. It will, therefore, be interesting to find out how miR156 modulates these physiological traits and hormone biosynthesis particularly ABA under heat stress.

\section{Functional processes affected by miR156 under heat stress}

MicroRNAs have emerged as a vital component of posttranscriptional regulation of genes involved in numerous growth, development and stress responses in plants. The inhibitory effect of abiotic stress on photosynthesis is mainly linked to stomatal conductivity and metabolic limitations that have widely been described in several 

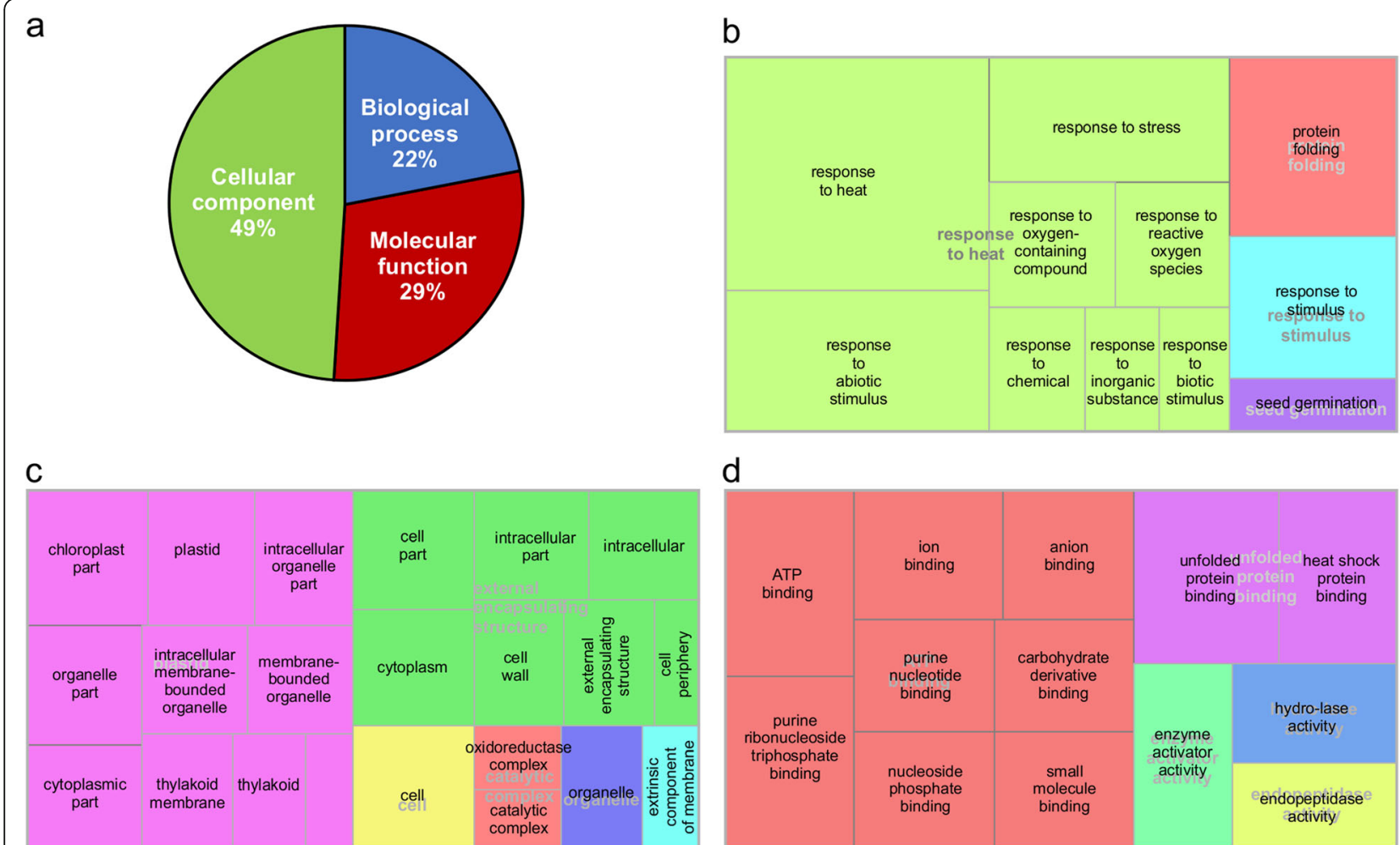

d

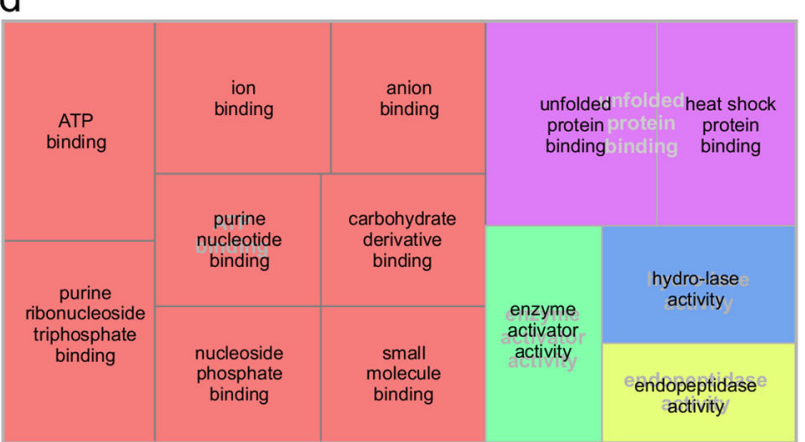

Fig. 3 Gene Ontology (GO) enrichment analysis, a Fractional distribution of GO terms based on molecular function, cellular component and biological process. Tree maps of $\mathbf{b}$ biological process, $\mathbf{c}$ cellular component and $\mathbf{d}$ molecular function of identified proteins with differentially altered abundance in EV controls under heat stress

other studies, including studies on heat shock response $[19,48,49]$. In our current study, a number of proteins with altered abundance became prominent when heat stress was imposed on controls and miR156OE plants. Although, the number of proteins with reduced abundance in miR156 during heat stress was similar to that of the control, the number of proteins with increased abundance was six times more than the controls. This suggests that miR156 may be activating proteins for various physiological processes to cope with heat stress conditions. Interestingly, there were only $10 \%$ proteins common between control and miR156OE genotype whose abundance was altered under heat, indicating that miR156 may be modulating abundance of several unique proteins under the stress. In the current study, miR156OE alfalfa proteins responded to heat stress by modifying physiological processes that represent major protein groups under heat stress.

\section{Photosynthesis}

A large portion of cellular component GO term in miR156, but not in control, consists of chloroplast, indicating that photosynthetic processes are being modulated by miR156. Interestingly, our recent publication has shown that miR156OE alfalfa exhibited increased chlorophyll content under heat stress in alfalfa [35], which supports the proteomic response of miR156OE alfalfa in the current study. Photosynthesis is one of the major processes affected by abiotic stress [36], and energy deficit is a common indicator of photosynthetic plants under stress [50]. Overall, stress reduces photosynthesis and respiration, which leads to energy deprivation and ultimately growth retardation and cell death [50]. PSII is a sensitive protein complex and its structure is altered under abiotic stress [51]. Some heat shock proteins (HSPs) are involved in protecting PSII under heat stress $[15,16,52]$. A previous study in alfalfa showed 23 proteins with altered abundance under heat stress, and these proteins belonged to the PSII and HSPs [5].

An increased abundance of the photosynthetic enzyme fructose-bisphosphate aldolase (FBA) during stress maintains the $\mathrm{CO}_{2}$ assimilation rate in alfalfa [5]. Enhanced FBA abundance specifically in miR156 genotype under heat stress highlights the role of miR156 in altering the abundance of these proteins and maintaining photosynthesis under high temperature in alfalfa. Some other photosynthesis-related proteins with enhanced abundance were also detected in this study, including the oxygen evolving enhancer protein (OEE). Abiotic stress, such as cold and heat, alter the abundance of 


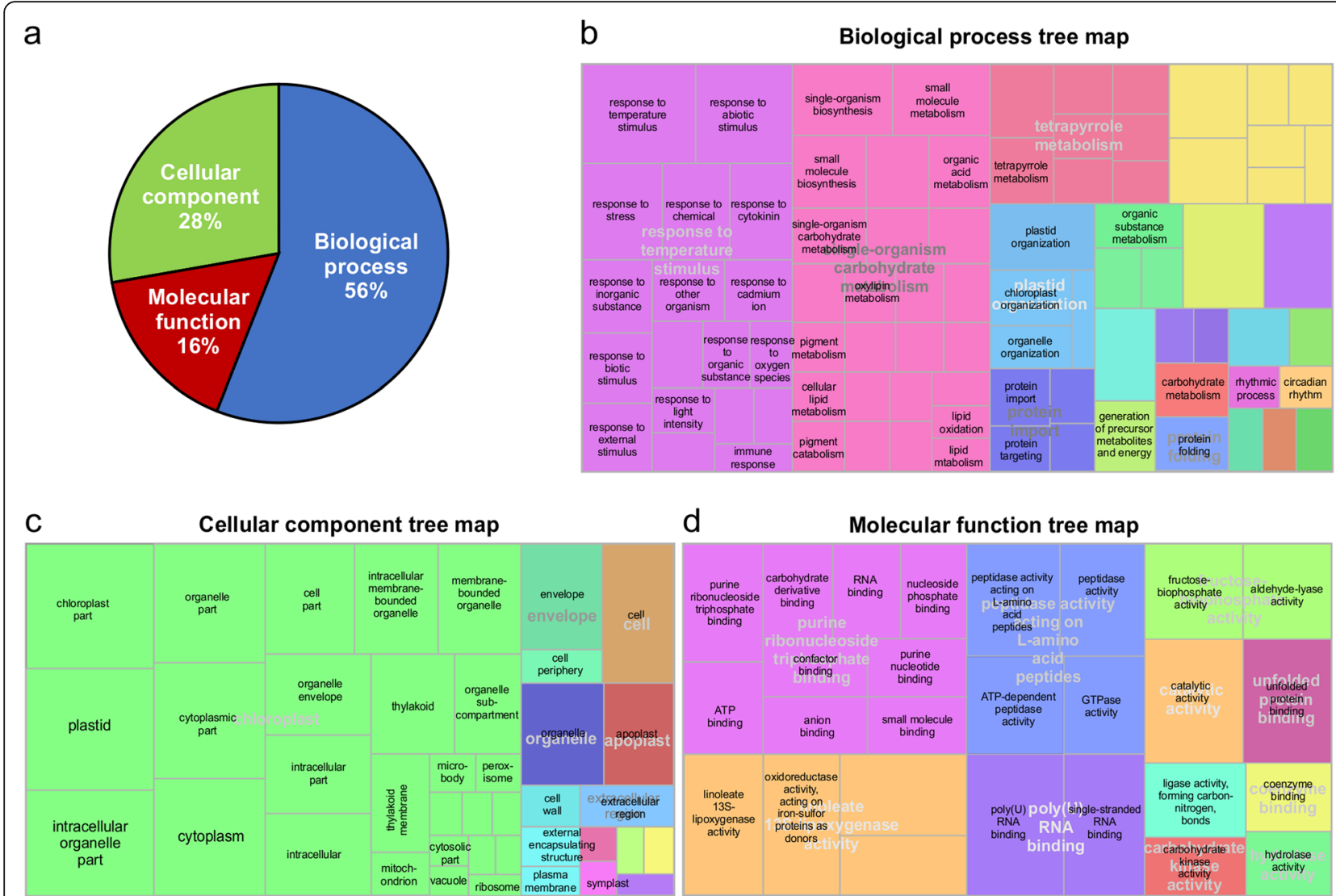

Fig. 4 Gene Ontology (GO) enrichment analysis, a Fractional distribution of GO terms based on molecular function, cellular component and biological process. Tree maps of $\mathbf{b}$ biological process, $\mathbf{c}$ cellular component and $\mathbf{d}$ molecular function of identified proteins with differentially altered abundance in miR156 overexpressing genotype (A8) under heat stress

OEE family in plants [53]. In several plant species, this protein abundance was altered under abiotic stress [54], and in the current study OEE abundance was increased specifically in miR156OE genotype upon heat treatment. This suggests that OEE may directly or indirectly be regulated by miR156 and contributes to stress tolerance in alfalfa.

\section{Metabolism}

Plants allocate a significant supply of $\mathrm{C}$ and $\mathrm{N}$ resources to the synthesis of metabolites under stress conditions to maintain adequate growth [55]. Increased metabolic activity may be a vital response to elevated temperature. A reduction in photosynthesis results in energy shortage, which leads to the enhancement of carbohydrate metabolism. Previous studies have shown enhanced expression of glutamine synthetase (GS) under abiotic stress conditions [56]. In the current study, increased GS abundance specifically in miR156 genotype under heat stress may indicate that miR156 regulates GS expression. GS plays a crucial role in ammonia assimilation, and increased expression of cytosolic GS enhanced photorespiration and contributed to photosynthesis protection under stress condition [57].

Our results showed an increased abundance of other proteins (e.g. G-6-PDH, Calnexin, beta-galactosidase and Chitinase) that were previously reported to play a role in abiotic stress tolerance in various plant species. For example, transgenic tobacco overexpressing two chitinases (CHIT33 and CHIT42) conferred tolerance to salinity and heavy metals without any detrimental effect on plant growth and development [58]. Calnexin (CNX) maintains calcium homeostasis in plants and overexpression of CNX in tobacco improved tolerance to dehydration and osmotic stress [59]. Overexpression of $\beta$ galactosidase enhanced stress tolerance in Arabidopsis by increasing leaf area and reducing senescence [60], and we also observed an increased abundance of $\beta$ galactosidase in miR156OE plants under heat stress. Moreover, our study revealed a reduced $\alpha$-galactosidase abundance in alfalfa under stress conditions, and these results are consistent with the previous research that showed down-regulation of $\alpha$-galactosidase and ultimately improved tolerance to low temperature in petunia [61]. These observations suggest that miR156 modulates 
Table 3 TF enrichment analysis showing TF families affected by specifically miR156 under heat stress conditions

\begin{tabular}{|c|c|}
\hline Transcription factor & Annotation \\
\hline Medtr6g086805 & heat shock transcription factor \\
\hline Medtr7g091370 & heat shock transcription factor \\
\hline Medtr4g022370 & Dof domain zinc finger protein \\
\hline Medtr3g077750 & Dof domain zinc finger protein \\
\hline Medtr8g005960 & squamosa promoter-binding-like protein \\
\hline Medtr2g099610 & MYB transcription factor MYB91 \\
\hline Medtr2g043050 & ethylene-responsive transcription factor ERF017-like protein \\
\hline Medtr5g016750 & ethylene response factor \\
\hline Medtr4g111975 & MYB-like transcription factor family protein \\
\hline Medtr4g119270 & ethylene response factor \\
\hline Medtr7g015010 & TCP family transcription factor \\
\hline Medtr2g067420 & myb transcription factor \\
\hline Medtr7g010210 & R2R3-myb transcription factor \\
\hline Medtr4g100630 & MYB-like transcription factor family protein \\
\hline Medtr6g092540 & MYB-like transcription factor family protein \\
\hline Medtr7g067080 & MYB transcription factor MYB51 \\
\hline Medtr7g083700 & B3 domain transcription factor \\
\hline Medtr7g080460 & AP2-like ethylene-responsive transcription factor \\
\hline Medtr4g108370 & TCP family transcription factor \\
\hline Medtr1g084980 & phytochrome-interacting factor 3.1 \\
\hline Medtr6g017055 & TCP family transcription factor \\
\hline Medtr8g033250 & MADS-box transcription factor \\
\hline Medtr1g102860 & heat shock transcription factor $\mathrm{A} 3$ \\
\hline Medtr3g101870 & heat shock transcription factor \\
\hline Medtr5g010680 & heat shock transcription factor B2A \\
\hline Medtr5g082950 & AP2 domain class transcription factor \\
\hline Medtr1g101810 & TCP family transcription factor \\
\hline Medtr7g028160 & TCP family transcription factor \\
\hline Medtr8g033070 & TCP family transcription factor \\
\hline Medtr5g026210 & beta-amylase-like protein \\
\hline Medtr1g062940 & myb transcription factor \\
\hline Medtr1g080920 & transcription factor bZIP88 \\
\hline Medtr7g104480 & ABA response element-binding factor \\
\hline Medtr8g070820 & bZIP transcription factor family protein \\
\hline Medtr1g022495 & BZIP transcription factor bZIP124 \\
\hline Medtr4g070860 & BZIP transcription factor bZIP124 \\
\hline Medtr7g029400 & BZIP transcription factor \\
\hline
\end{tabular}

heat stress response in alfalfa by regulating some important proteins involved in physiological and metabolic processes.

\section{Defense}

Heat shock proteins (HSPs) are low molecular weight chaperones that play a vital role in providing plants with protection against stress by re-establishing normal protein conformation and cellular homeostasis, as well as assisting in protein refolding under stress. $\mathrm{Li}$ et al. (2013) detected 19 alfalfa proteins that belonged to the HSP group, most of which showed increased abundance in response to heat stress in alfalfa [5]. In contrast, a decrease in abundance of all HSPs (except one) and small 
heat shock protein (sHSP) was detected under heat stress in both control and miR156 genotypes. Plants induce expression of HSPs as an adaptive strategy for tolerance to heat stress. There are however substantial variations of HSP expression patterns in different plant species and even between genotypes of the same species [62]. Expression of four rice HSPs was rapidly increased under heat stress but two HSPs showed reduced expression after $3 \mathrm{~h}$ of heat stress in the same study, indicating that different $H S P$ s were regulated by different time patterns or by different signals and may be affiliated with different functions in response to heat [62]. A repressive function of HSPs in this study is consistent with the finding that reduced HSP levels stimulated growth in Arabidopsis [63]. These differential responses by HSPs are of particular interest in the study of thermotolerance reactions in plants $[15,63]$ and need to be further investigated.

The small HSPs are of particular interest since they appear to protect PS II and thylakoid membranes under heat stress in plants [64]. Two studies have demonstrated the role of sHSPs in protecting the photosynthesis machinery. For example, sHSP interacts with proteins of the thermolabile oxygen-evolving complex (OEC) of PS II in Chenopodium album [65]. Similarly, an increase in sHSP26 abundance was found to improve the photochemical efficiency of PS II under heat stress in tall fescue [66]. These observations suggest that sHSPs can alter OEC proteins of PS II, pinpointing an important role for sHSPs in modulating plant response under high temperature. Although sHSPs may play a substantial role in protecting photosynthetic proteins against stress, more research is still needed to understand the underlying mechanisms governing the regulation of their biosynthesis and physiological functions, including their role in heat tolerance in plants under the influence of miR156.

Environmental stress, including high temperature, causes a rapid and excessive accumulation of reactive oxygen species (ROS) in plants. Excessive levels of stressinduced ROS are removed by enzymatic and nonenzymatic antioxidants [36]. This study showed an increased abundance of G-6-PHD and CNX in miR156OE plants under heat stress, and this is consistent with previous studies, which have shed light on the role of CNX in ROS signaling, scavenging ROS and improving oxidative stress response in plants [59, 67]. Similarly, Liu et al. (2007) revealed that G-6-PDH plays a crucial role in nitric oxide-dependant defence against oxidative stress, resulting in improved salt tolerance in red kidney beans [67].

\section{MicroRNA156 affects various transcription factors under heat stress}

Transcription factors (TFs) play a crucial role in regulating molecular response under abiotic stress in plants. In the current study, we detected TCP, bZIP, ethylene responsive factor (ERF) and SQUAMOSA-PROMOTER BINDING PROTEIN-LIKE (SPL) by TF enrichment analysis, and our previous study showed an altered expression of these TFs under drought stress in miR156OE alfalfa [23]. This may indicate that miR156 regulates these TFs not only under drought but also heat stress conditions. The SPLs are known targets of miR156, and our recent studies have shown that reduced SPL13 expression improved drought [25] and heat [35] stress tolerance in alfalfa. Given the diversity of important TFs targeted by miR156, and the physiological traits affected by miR156 in alfalfa, it is critical to identify and characterize these TFs and their downstream targets to further elucidate the role of miR156-regulated network in stress tolerance.

\section{Conclusion}

In this study, we conducted label-free quantitative proteomics analysis on miR156OE alfalfa under heat stress. Our biochemical data showed that miR156OE plants accumulated higher levels of proline and antioxidants when exposed to elevated temperature (Fig. 5). Furthermore, LC-MS/MS analysis revealed differential abundance of a range protein groups in miR156OE plants under heat stress. We detected 91 proteins that were unique to miR156OE (undetected in EV alfalfa) and belong to critical functional groups such as plant defence, photosynthesis and metabolism. These proteins and identified TFs showed differentially altered abundance only under heat stress, and could potentially be regulated directly or indirectly by miR156 (Fig. 5). In summary, the results from this study have increased our understanding of miR156 and miR156-mediated regulation that could result in potential tangible targets for practical applications in alfalfa and related legume species to address abiotic stress limitations to agricultural productivity. Transcription factors play an important role in regulating the molecular response of plants to stress. Detection of expression changes by transcriptome sequencing analysis in alfalfa could identify genes and transcription factors involved in heat stress tolerance. Therefore, future research should focus on combining physiology with the transcriptome, metabolome, and proteome under the influence of miR156 to provide better insights into the crosstalk between different functional pathways and the regulatory mechanisms controlled by miR156 for heat tolerance in plants.

\section{Methods}

Plant material, experimental design, and heat treatment A miR156 overexpressing (miR156OE) alfalfa genotype (A8) was generated by our group in a previous study [21]. Rooted stem cuttings were made from A8 and 


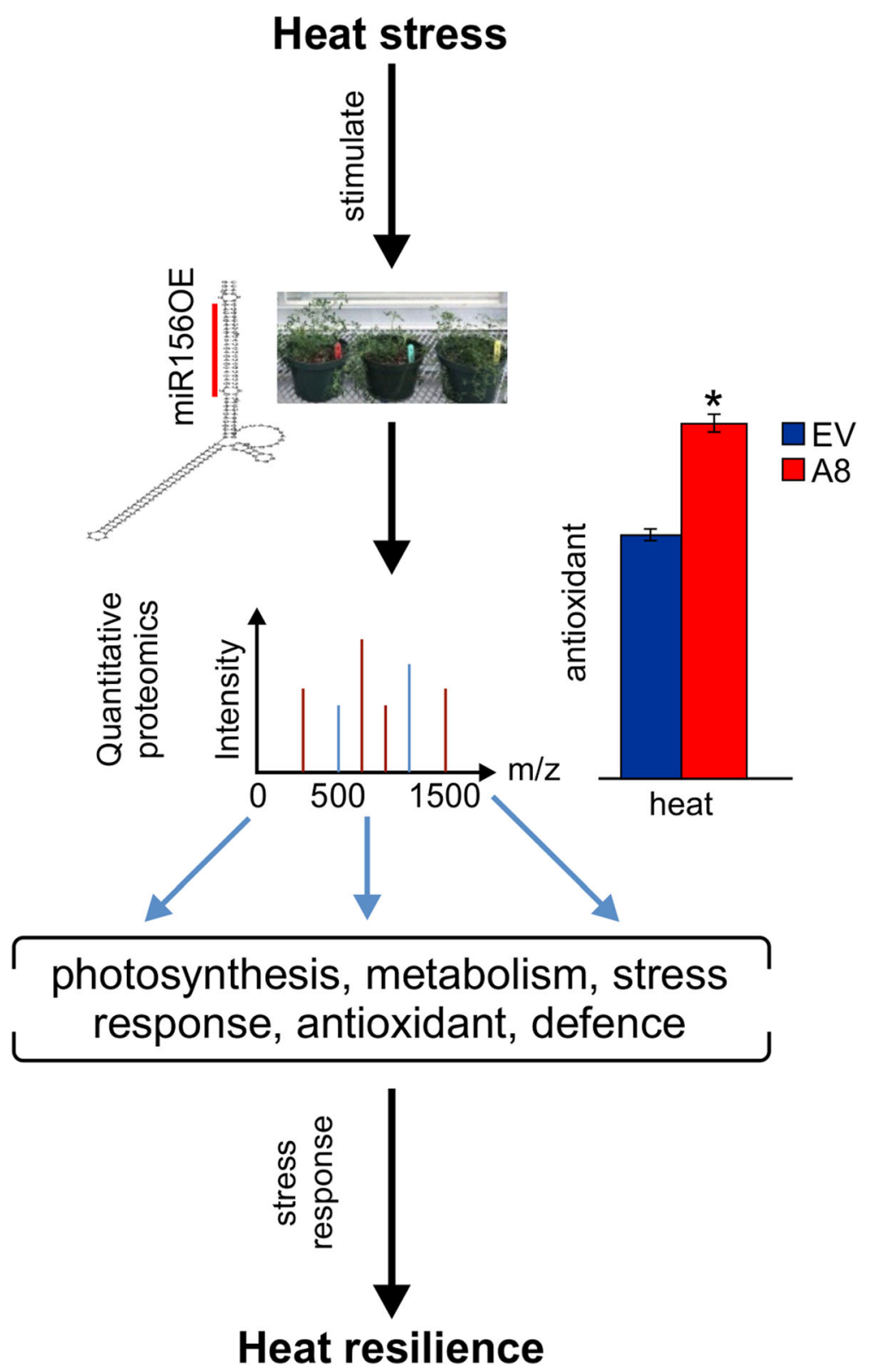

Fig. 5 A proposed model of miR156-regulated heat stress response in alfalfa

empty vector (EV) control plant. Stem cuttings were transferred to $51 / 2$ " standard pots containing homogenized PRO-MIX ${ }^{\odot} \mathrm{BX}$ soil. Emerging plants were then grown on the bench in the greenhouse under a 16- $h$ light/ 8-h dark regime and watered twice weekly. A randomized experiment was designed and a heat stress trial was started on two-month-old plants of EV and A8, which were randomly assigned to non-stressed control or heat treatments. Heat stress treatment was set up as described in our published study [35]. A minimum of three plants from each genotype were completely randomized in one growth cabinet for heat treatment after watering them to field capacity, whereas the same number of plants were kept in the greenhouse for the non-stress control experiment. Growth cabinet temperature for the heat stress treatment was set to $40^{\circ} \mathrm{C}$ and the same photoperiod and light intensity were used as in the greenhouse. Whole plant shoot (aboveground portion) tissues from at least three plants from each of A8 and EV under non-stressed control $\left(22^{\circ} \mathrm{C}\right)$, and after $24 \mathrm{~h}$ of heat treatment $\left(40^{\circ} \mathrm{C}\right)$, were collected in separate falcon tubes which were immediately frozen in liquid nitrogen and stored at $-80^{\circ} \mathrm{C}$ for further analysis. Frozen shoot tissues from each plant were ground separately into a fine powder with mortal and pestle in liquid nitrogen. Samples required for protein extraction, 
and proline and antioxidant assays were obtained from this fine powder mixture.

\section{Proline and antioxidant assays}

Proline and antioxidant assays were performed on at least three plants (three biological replicates) from each genotype (EV and A8) obtained from each non-stressed control and heat stressed conditions. Proline measurements were conducted by following a previously described protocol [68]. Briefly, $0.5 \mathrm{~g}$ leaf samples were homogenized in $10 \mathrm{ml}$ of $3 \%$ sulfosalicylic acid followed by filtration through Whatman \#2 filter paper. Subsequently, $2 \mathrm{~mL}$ of filtrate was mixed with an equal volume of acid-ninhydrin and glacial acetic acid and reacted at $100{ }^{\circ} \mathrm{C}$ for $1 \mathrm{~h}$. The reaction was terminated by cooling on ice, followed by extraction with toluene. The proline content was determined by measuring the absorbance of the supernatant at $520 \mathrm{~nm}$ using a plate reader (BioTek, Synergy 2, Winooski, VT) and comparing the values to a standard curve as described in previously published study [26].

For antioxidant measurements, approximately $100 \mathrm{mg}$ of samples were used by following the protocol of an antioxidant assay kit (Sigma-Aldrich, Oakville ON; catalogue number CS0790). Trolox standards were prepared following the protocol provided in the kit. Assays were conducted in a 96-well plate by reading the endpoint absorbance at $405 \mathrm{~nm}$ in the plate reader (BioTek). Antioxidant concentration in the samples was calculated by comparing it to Trolox standard curve [26].

\section{Protein extraction, lysis, and digestion}

Protein extraction was performed as described in Marx et al. (2016) [62]. Briefly, leaf samples from three nonstressed control and three heat stressed plants from each of the EV and A8 genotypes were ground into a powder using a mortal and a pestle in liquid nitrogen. The extraction buffer ( $290 \mathrm{mM}$ sucrose, $250 \mathrm{mM}$ TRIS (pH 7.6), $25 \mathrm{mM}$ EDTA (pH 8.0), $10 \mathrm{mM} \mathrm{KCl,} 25 \mathrm{mM} \mathrm{NaF}, 50$ $\mathrm{mM}$ Na pyrophosphate, $1 \mathrm{mM}$ ammonium molybdate, 1 $\mathrm{mM}$ PMSF, $1 \mu \mathrm{g} / \mathrm{mL}$ leupeptin, $1 \mu \mathrm{g} / \mathrm{mL}$ pepstatin, $1 \mu \mathrm{g} /$ $\mathrm{mL}$ aprotinin) [69], and five times volume was added to each sample. The sample mix was then subjected to 3 min probe sonication followed by filtration through Miracloth. Chloroform/methanol was used to precipitate the protein from the sample extract. The obtained protein pellet was washed with $80 \%$ cold acetone, air dried for $1 \mathrm{~h}$ and used in subsequent steps. The protein pellet was dissolved in lysis buffer $(8 \mathrm{M}$ urea, $50 \mathrm{mM}$ Tris- $\mathrm{HCl}$ (pH 8), $30 \mathrm{mM} \mathrm{NaCl}, 1 \mathrm{mM} \mathrm{CaCl}_{2}, 20 \mathrm{mM}$ sodium butyrate, $10 \mathrm{mM}$ nicotinamide, a mini EDTA-free protease inhibitor, and phosSTOP phosphatase inhibitor), followed by additional sonication. The protein content was measured using a bicinchoninic acid (BCA) assay
(Thermo Fisher Scientific, Waltham, MA). Subsequently, $75 \mu \mathrm{g}$ protein were reduced with dithiothreitol and alkylated with $15 \mathrm{mM}$ iodoacetamide. Protein digestion was carried out in two steps. First, LysC (Thermo Fisher Scientific) was added followed by incubation at $37^{\circ} \mathrm{C}$ for $2.5 \mathrm{~h}$. Second, samples were diluted using $50 \mathrm{mM}$ Tris and $5 \mathrm{mM} \mathrm{CaCl}$. Mass Spec-grade trypsin protease (Thermo Fisher Scientific) was then added to the mixture, which was incubated overnight at ambient temperature. The digestion reaction was quenched by bringing $\mathrm{pH} \sim 2$ using trifluoroacetic acid, immediately desalted using Waters Oasis HLB ( $1 \mathrm{ml}, 30 \mathrm{mg}$ sorbent), and the eluent was dried by vacuum centrifugation. Samples were reconstituted in $75 \mu \mathrm{L}$ of $0.1 \%$ formic acid and transferred to an HPLC vial.

The peptide digests were separated on an Easy-nLC 1000 nano-flow HPLC system equipped with a $2 \mathrm{~cm}$ Acclaim C18 PepMap ${ }^{\text {Ta }}$ trap column and a $75 \mu \mathrm{m} \times 25 \mathrm{~cm}$ Acclaim C18 PepMap ${ }^{\text {tm }}$ analytical column (Thermo Scientific). The flow rate was held at $300 \mathrm{~nL} \mathrm{~min}^{-1}$ throughout the run and $10 \mu \mathrm{L}$ of the digest was injected. The mobile phase A (97\%) (LC/MS Optima water, 0.1\% formic acid) was first decreased to $90 \%$ over $4 \mathrm{~min}$. Peptides were then eluted with a linear gradient of 10 to $40 \%$ mobile phase B (LC/MS Optima acetonitrile, $0.1 \%$ formic acid) over $150 \mathrm{~min}$, followed by $40-90 \%$ over 10 min, and maintained constant for an additional $10 \mathrm{~min}$. Each sample was then analyzed using a top 10, datadependent acquisition method in the mass range of $\mathrm{m} / \mathrm{z}$ 300-2000 using a Thermo Q-Exactive Orbitrap mass spectrometer coupled to an Agilent 1290 HPLC system. The nanospray voltage was set at $2.4 \mathrm{kV}$, capillary temperature at $275^{\circ} \mathrm{C}$, and the S-lens radio frequency (RF) level at 70. The full scan was acquired at 70,000 resolution with an automatic gain control (AGC) of $1 \times$ $10^{6}$ and a maximum injection time (IT) of $250 \mathrm{msec}$. The MS/MS scans were acquired at 17,500 resolution, AGC of $5 \times 10^{5}$, maximum IT of $110 \mathrm{msec}$, intensity threshold of $1 \times 10^{5}$, normalized collision energy of 27 and an isolation window of $1.7 \mathrm{~m} / z$. Unassigned, singly charged, and $>4$ charged peptides were not selected for MS/MS, and a $30 \mathrm{~s}$ dynamic exclusion was used.

\section{LC-MS/MS data analysis Data analysis with MaxQuant}

Alfalfa (Medicago sativa) genome has not been sequenced and therefore we used its close relative Medicago truncatula for analysis. The Thermo ${ }^{\circ}$ raw files were searched against the related species Medicago truncatula protein sequence database (Uniprot UP000002051, accessed December 21st 2019) with MaxQuant software (1.6.1.0) [41]. Searches were conducted using default precursor mass tolerances $(20 \mathrm{ppm}$ for first search and 4.5 for the main search). Trypsin and LysC were selected 
as enzymes with a maximum of two missed cleavages. Carbamidomethylation was selected as fixed modification, and oxidation of methionine residues as variable modification. The false discovery rate (FDR) for peptide and protein identification was set to $5 \%$, and minimum peptide length was set to seven amino acids. Proteins that were identified by MS/MS in a minimum of three samples biological samples were retained. The MaxLFQ algorithm for label-free quantification (LFQ) and the "Matching between the runs" feature was enabled [41]. The data was imported into Perseus software (http:// www.perseus-framework.org) for LFQ comparisons and missing values were imputed with default settings. Only protein groups with measured LFQ values in two of the three sample replicates were retained. The raw mass spectrometry data and the MAXQUANT output files were deposited to the ProteomeXchange Consortium via the PRIDE partner repository with the dataset identifier PXD019560.

\section{GO and TF enrichment analysis}

Identified proteins were annotated using the Uniprot database [70]. M. truncatula GO terms for the selected proteins were searched from the PlantRegMap using GO Term enrichment tool [71, 72], and all the proteins identified with significant altered abundance in this study were used as input to carry out GO enrichment analysis. The enriched GO terms were summarized and plotted following the published REVIGO protocol $[37,73]$. The ratios of molecular functions, cellular component and biological process were calculated based on the number of GO terms. TF enrichment was performed by blasting Uniprot IDs of the 91 proteins unique to miR156 against M. truncatula TF database. The TFs were identified based on the functional transcription factor binding site feature [72]. Venn diagrams were generated using the Venny tool [74].

\section{Statistical analysis}

GraphPad Prism software (https://www.graphpad.com/ scientific-software/prism/) was used to statistically test significance of the data. For comparisons between two groups, the Student t-test was used, whereas Perseus software was used to compare protein groups obtained from MaxQuant data.

\section{Abbreviations \\ miR156: microRNA156; miR156OE: microRNA overexpression; FBA: Fructose- bisphosphate aldolase; G-6-PDH: Glucose-6-phosphate 1-dehydrogenase; LFQ: Label-free quantification}

\section{Acknowledgements}

We thank Alex Molnar for his assistance with figures.

\section{Authors' contributions}

MA designed the project, conducted experiments and analyzed data. MA drafted the manuscript and handled the authors/reviewers comments. AP helped in protein extraction, and AJS helped with proteomic data analysis. JR performed the LC-MS/MS and MaxQuant analysis, and edited the manuscript. MYG and FM edited the manuscript. AH secured funding, oversaw the project and edited manuscript. All authors have read and approved the manuscript.

\section{Funding}

Agriculture and Agri-Food Canada supported this work through a research grant to AH. MA was a recipient of an NSERC Visiting Fellowship in Canadian Government Laboratories. The funding bodies played no role in the design of the study and collection, analysis, and interpretation of data and in writing the manuscript.

\section{Availability of data and materials}

The raw mass spectrometry data and the MAXQUANT output files were deposited to the ProteomeXchange Consortium via the PRIDE partner repository with the dataset identifier PXD019560.

Ethics approval and consent to participate

Not applicable.

Consent for publication

Not applicable.

\section{Competing interests}

The authors declare that they have no competing interests.

\section{Author details}

Agriculture and Agri-Food Canada, 1391 Sandford Street, London, Ontario N5V 4T3, Canada. ${ }^{2}$ Centre for Genomics and Systems Biology, New York University, Abu Dhabi, United Arab Emirates. ${ }^{3}$ Department of Biology, University of Western Ontario, 1151 Richmond Street, London, Ontario N6A 5B7, Canada. ${ }^{4}$ Agriculture and Agri-Food Canada, 107 Science Place, Saskatoon, Saskatchewan S7N 0X2, Canada.

Received: 7 June 2020 Accepted: 19 October 2020

Published online: 02 November 2020

\section{References}

1. Zahran HH. Rhizobium-legume symbiosis and nitrogen fixation under severe conditions and in an arid climate. Microbiol Mol Biol Rev. 1999;63: 968-89.

2. Li S, Li F, Wang J, Zhang W, Meng Q, Chen TH, Murata N, Yang X. Glycinebetaine enhances the tolerance of tomato plants to high temperature during germination of seeds and growth of seedlings. Plant Cell Environ. 2011;34:1931-43. https://doi.org/10.1111/j.1365-3040.2011. 02389.x

3. Vollenweider P, Gunthardt-Goerg MS. Diagnosis of abiotic and biotic stress factors using the visible symptoms in foliage. Environ Pollut. 2006;140:562-71.

4. Battisti DS, Naylor RL. Historical warnings of future food insecurity with unprecedented seasonal heat. Science. 2009;323:240-4. https://doi.org/10. 1126/science.1164363.

5. Li W, Wei Z, Qiao Z, Wu Z, Cheng L, Wang Y. Proteomics analysis of alfalfa response to heat stress. PLoS One. 2013;8:e82725. https://doi.org/10.1371/ journal.pone.0082725.

6. Hu W, Kong H, Guo Y, Zhang Y, Ding Z, Tie W, Yan Y, Huang Q, Peng M, Shi $H$, Guo A. Comparative physiological and transcriptomic analyses reveal the actions of melatonin in the delay of postharvest physiological deterioration of cassava. Front Plant Sci. 2016;7:736. https://doi.org/10.3389/fpls.2016. 00736.

7. Kamal AHM, Komatsu S. Jasmonic acid induced protein response to biophoton emissions and flooding stress in soybean. J Proteome. 2016;133: 33-47. https://doi.org/10.1016/j.jprot.2015.12.004.

8. Staudinger C, Mehmeti-Tershani V, Gil-Quintana E, Gonzalez EM, Hofhansl F, Bachmann G, Wienkoop S. Evidence for a rhizobia-induced drought stress response strategy in Medicago truncatula. J Proteome. 2016;136:202-13. https://doi.org/10.1016/j.jprot.2016.01.006.

9. Ma Q, Kang J, Long R, Zhang T, Xiong J, Zhang K, Wang T, Yang Q, Sun Y, Comparative proteomic analysis of alfalfa revealed new salt and drought stress-related factors involved in seed germination. Mol Biol Rep. 2017:44: 261-72. https://doi.org/10.1007/s11033-017-4104-5. 
10. Zhang C, Shi S. Physiological and proteomic responses of contrasting alfalfa (Medicago sativa L.) varieties to PEG-induced osmotic stress. Front Plant Sci. 2018;9:242. https://doi.org/10.3389/fpls.2018.00242.

11. Xiong J, Sun Y, Yang Q, Tian H, Zhang H, Liu Y, Chen M. Proteomic analysis of early salt stress responsive proteins in alfalfa roots and shoots. Proteome Sci. 2017;15:19. https://doi.org/10.1186/s12953-017-0127-z.

12. Chen L, Chen Q, Zhu Y, Hou L, Mao P. Proteomic identification of differentially expressed proteins during alfalfa (Medicago sativa L.) flower development. Front Plant Sci. 2016;7:1502. https://doi.org/10.3389/fpls.2016.01502.

13. Heazlewood $J$ L. The green proteome: challenges in plant proteomics. Front Plant Sci. 2011;2:6. https://doi.org/10.3389/fpls.2011.00006.

14. Carroll AW, Joshi HJ, Heazlewood JL. Managing the green proteomes for the next decade of plant research. Front Plant Sci. 2013;4:501. https://doi. org/10.3389/fpls.2013.00501.

15. Lee DG, Ahsan N, Lee SH, Kang KY, Bahk JD, Lee IJ, Lee BH. A proteomic approach in analyzing heat-responsive proteins in rice leaves. Proteomics. 2007;7:3369-83. https://doi.org/10.1002/pmic.200700266.

16. Zou J, Liu C, Chen X. Proteomics of rice in response to heat stress and advances in genetic engineering for heat tolerance in rice. Plant Cell Rep. 2011;30:2155-65. https://doi.org/10.1007/s00299-011-1122-y.

17. Wei YJ, Huang YX, Shen Y, Cui CJ, Zhang XL, Zhang H, Hu SS. Proteomic analysis reveals significant elevation of heat shock protein 70 in patients with chronic heart failure due to arrhythmogenic right ventricular cardiomyopathy. Mol Cell Biochem. 2009;332:103-11. https://doi.org/10. 1007/s11010-009-0179-1.

18. Jones-Rhoades MW, Bartel DP, Bartel B. MicroRNAs and their regulatory roles in plants. Annu Rev Plant Biol. 2006;57:19-53. https://doi.org/10.1146/ annurev.arplant.57.032905.105218.

19. Hannoufa A, Matthews C, Feyissa BA, Gruber MY, Arshad M. Progress toward deep sequencing-based discovery of stress-related microRNA in plants and available bioinformatics tools. In: Progress in Botany 81. Berlin, Heidelberg: Springer; 2018. https://doi.org/10.1007/124_2018_25.

20. Axtell MJ. Classification and comparison of small RNAs from plants. Annu Rev Plant Biol. 2013;64:137-59. https://doi.org/10.1146/annurev-arplant050312-120043.

21. Aung B, Gruber MY, Amyot L, Omari K, Bertrand A, Hannoufa A. MicroRNA156 as a promising tool for alfalfa improvement. Plant Biotechnol J. 2015;13:779-90. https://doi.org/10.1111/pbi.12308.

22. Aung B, Gruber MY, Amyot L, Omari K, Bertrand A, Hannoufa A. Ectopic expression of LjmiR156 delays flowering, enhances shoot branching, and improves forage quality in alfalfa. Plant Biotechnol Rep. 2015;9:379-93. https://doi.org/10.1007/s11816-015-0375-2.

23. Arshad M, Gruber M, Hannoufa A. Transcriptome analysis of microRNA156 overexpression alfalfa roots under drought stress. Sci Rep. 2018;8:9363. https://doi.org/10.1038/s41598-018-27088-8

24. Cardon G, Höhmann S, Klein J, Nettesheim K, Saedler H, Huijser P. Molecular characterisation of the Arabidopsis SBP-box genes. Gene. 1999;237:91-104.

25. Gao R, Gruber MY, Amyot L, Hannoufa A. SPL13 regulates shoot branching and flowering time in Medicago sativa. Plant Mol Biol. 2018;96:119-33. https://doi.org/10.1007/s11103-017-0683-8

26. Arshad M, Feyissa BA, Amyot L, Aung B, Hannoufa A. MicroRNA156 improves drought stress tolerance in alfalfa (Medicago sativa) by silencing SPL13. Plant Sci. 2017;258:122-36. https://doi.org/10.1016/j.plantsci.2017.01.018.

27. Arshad M, Gruber MY, Wall K, Hannoufa A. An insight into microRNA156 role in salinity stress responses of alfalfa. Front Plant Sci. 2017;8:356. https://doi.org/10.3389/fpls.2017.00356.

28. Claussen W. Proline as a measure of stress in tomato plants. Plant Sci. 2005; 168:241-8. https://doi.org/10.1016/j.plantsci.2004.07.039.

29. Rivero R, Ruiz M, Romero LM. Importance of $N$ source on heat stress tolerance due to the accumulation of proline and quaternary ammonium compounds in tomato plants. Plant Biol. 2004;6:702-7. https://doi.org/10. 1055/s-2004-821293.

30. Hamilton EW. Mitochondrial adaptations to $\mathrm{NaCl}$. Complex I is protected by anti-oxidants and small heat shock proteins, whereas complex $\|$ is protected by proline and betaine. Plant Physiol. 2001;126:1266-74. https://doi.org/10.1104/pp.126.3.1266.

31. Tonhati R, Mello SC, Momesso P, Pedroso RM. L-proline alleviates heat stress of tomato plants grown under protected environment. Sci Hortic. 2020;268: 109370. https://doi.org/10.1016/j.scienta.2020.109370.

32. Abdula SE, Lee HJ, Ryu H, Kang KK, Nou I, Sorrells ME, Cho YG. Overexpression of BrCIPK1 gene enhances abiotic stress tolerance by increasing proline biosynthesis in rice. Plant Mol Biol Rep. 2016;34:501-11. https://doi.org/10.1007/s11105-015-0939-x.

33. Kaushal N, Gupta K, Bhandhari K, Kumar S, Thakur P, Nayyar H. Proline induces heat tolerance in chickpea (Cicer arietinum L.) plants by protecting vital enzymes of carbon and antioxidative metabolism. Physiol Mol Biol Plants. 2011;17:203. https://doi.org/10.1007/s12298-011-0078-2.

34. Oukarroum A, Madidi ES, Strasser RJ. Exogenous glycine betaine and proline play a protective role in heat-stressed barley leaves (Hordeum vulgare L.): a chlorophyll a fluorescence study. Plant Biosystems-An Int J Deal Aspects Plant Biol. 2012;146:1037-43. https://doi.org/10.1080/11263504.2012.697493.

35. Matthews $C$, Arshad M, Hannoufa A. Alfalfa response to heat stress is modulated by microRNA156. Physiol Plant. 2019;165:830-42. https://doi.org/ 10.1111/ppl.12787.

36. Ashraf M. Inducing drought tolerance in plants: recent advances. Biotechnol Adv. 2010;28:169-83. https://doi.org/10.1016/j.biotechadv.2009.11.005.

37. Gao R, Austin RS, Amyot L, Hannoufa A. Comparative transcriptome investigation of global gene expression changes caused by miR156 overexpression in Medicago sativa. BMC Genomics. 2016;17. https://doi.org/ 10.1186/s12864-016-3014-6.

38. Feyissa BA, Arshad M, Gruber MY, Kohalmi SE, Hannoufa A. The interplay between miR156/SPL13 and DFR/WD40-1 regulate drought tolerance in alfalfa. BMC Plant Biol. 2019;19:1-19. https://doi.org/10.1186/s12870-0192059-5.

39. Teixeira El, Fischer G, Van Velthuizen H, Walter C, Ewert F. Global hot-spots of heat stress on agricultural crops due to climate change. Agric Forest Meteorol. 2013;170:206-15. https://doi.org/10.1016/j.agrformet.2011.09.002

40. Wahid A, Gelani S, Ashraf M, Foolad MR. Heat tolerance in plants: an overview. Environ Exp Bot. 2007;61:199-223. https://doi.org/10.1016/j. envexpbot.2007.05.011.

41. Cox J, Hein MY, Luber CA, Paron I, Nagaraj N, Mann M. Accurate proteomewide label-free quantification by delayed normalization and maximal peptide ratio extraction, termed MaxLFQ. Mol Cell Proteomics. 2014;13: 2513-26. https://doi.org/10.1074/mcp.M113.031591.

42. Gilroy S, Bialasek M, Suzuki N, Gorecka M, Devireddy AR, Karpinski S, Mittler R. ROS, calcium, and electric signals: key mediators of rapid systemic signaling in plants. Plant Physiol. 2016;171:1606-15. https://doi.org/10.1104/ pp.16.00434

43. Anjum NA, Aref IM, Duarte AC, Pereira E, Ahmad I, labal M. Glutathione and proline can coordinately make plants withstand the joint attack of metal(loid) and salinity stresses. Front Plant Sci. 2014;5. https://doi.org/10. 3389/fpls.2014.00662.

44. Cui LG, Shan JX, Shi M, Gao JP, Lin HX. The miR156-SPL9-DFR pathway coordinates the relationship between development and abiotic stress tolerance in plants. Plant J. 2014;80:1108-17. https://doi.org/10.1111/tpj.12712.

45. Li N, Zhang S, Liang YJ, Qi YH, Chen J, Zhu WN, Zhang LS. Label-free quantitative proteomic analysis of drought stress-responsive late embryogenesis abundant proteins in the seedling leaves of two wheat (Triticum aestivum L.) genotypes. J Proteome. 2018;172:122-42. https://doi. org/10.1016/j.jprot.2017.09.016.

46. Das A, Eldakak M, Paudel B, Kim DW, Hemmati H, Basu C, Rohila JS. Leaf proteome analysis reveals prospective drought and heat stress response mechanisms in soybean. Biomed Res Int. 2016. https://doi.org/10.1155/ 2016/6021047.

47. Sah SK, Reddy KR, Li JX. Abscisic acid and abiotic stress tolerance in crop plants. Front Plant Sci. 2016;7. https://doi.org/10.3389/fpls.2016.00571.

48. Chaves MM, Flexas J, Pinheiro C. Photosynthesis under drought and salt stress: regulation mechanisms from whole plant to cell. Ann Bot. 2009;103: 551-60. https://doi.org/10.1093/aob/mcn125.

49. Lawlor DW, Tezara W. Causes of decreased photosynthetic rate and metabolic capacity in water-deficient leaf cells: a critical evaluation of mechanisms and integration of processes. Ann Bot. 2009;103:561-79. https://doi.org/10.1093/aob/men244.

50. Baena-Gonzalez E, Rolland F, Thevelein JM, Sheen J. A central integrator of transcription networks in plant stress and energy signalling. Nature. 2007; 448:938-U910. https://doi.org/10.1038/nature06069.

51. Yin Y, Li SM, Liao WQ, Lu QT, Wen XG, Lu CM. Photosystem ॥ photochemistry, photoinhibition, and the xanthophyll cycle in heat-stressed rice leaves. J Plant Physiol. 2010;167:959-66. https://doi.org/10.1016/j.jplph. 2009.12.021

52. Liu GT, Ma L, Duan W, Wang BC, Li JH, Xu HG, Yan XQ, Yan BF, Li SH, Wang LJ. Differential proteomic analysis of grapevine leaves by iTRAQ reveals 
responses to heat stress and subsequent recovery. BMC Plant Biol. 2014;14 110. https://doi.org/10.1186/1471-2229-14-110.

53. Rinalducci S, Egidi MG, Karimzadeh G, Jazii FR, Zolla L. Proteomic analysis of a spring wheat cultivar in response to prolonged cold stress. Electrophoresis. 2011;32:1807-18. https://doi.org/10.1002/elps.201000663.

54. Oukarroum A, Schansker G, Strasser RJ. Drought stress effects on photosystem I content and photosystem II thermotolerance analyzed using $\mathrm{Chl}$ a fluorescence kinetics in barley varieties differing in their drought tolerance. Physiol Plant. 2009;137:188-99. https://doi.org/10.1111/j.13993054.2009.01273.x.

55. Aranjuelo I, Molero G, Erice G, Avice JC, Nogues S. Plant physiology and proteomics reveals the leaf response to drought in alfalfa (Medicago sativa L.). J Exp Bot. 2011;62:111-23. https://doi.org/10.1093/jxb/erq249.

56. Sahu AC, Sahoo SK, Sahoo N. NaCl-stress induced alteration in glutamine synthetase activity in excised senescing leaves of a salt-sensitive and a salttolerant rice cultivar in light and darkness. Plant Growth Regul. 2001;34:287-92. https://doi.org/10.1023/A:1013395701308,

57. el-Khatib RT, Hamerlynck EP, Gallardo F, Kirby EG. Transgenic poplar characterized by ectopic expression of a pine cytosolic glutamine synthetase gene exhibits enhanced tolerance to water stress. Tree Physiol. 2004:24:729-36.

58. de las Mercedes Dana M, Pintor-Toro JA, Cubero B. Transgenic tobacco plants overexpressing chitinases of fungal origin show enhanced resistance to biotic and abiotic stress agents. Plant Physiol. 2006;142:722-30.

59. Sarwat M, Naqvi AR. Heterologous expression of rice calnexin (OsCNX) confers drought tolerance in Nicotiana tabacum. Molecular Biol Rep. 2013; 40:5451-64.

60. Ban Q, Jiao J, He Y, Jin M, Rao J. Ectopic expression of the persimmon $\beta$ galactosidase gene DKGAL2 promotes leaf growth, delays dark-induced senescence and enhances tolerance to abiotic stress in Arabidopsis. Sci Hortic. 2020;265:109232. https://doi.org/10.1016/j.scienta.2020.109232.

61. Pennycooke JC, Jones ML, Stushnoff C. Down-regulating a-galactosidase enhances freezing tolerance in transgenic petunia. Plant Physiol. 2003;133: 901-9. https://doi.org/10.1104/pp.103.024554.

62. Bita $C E$, Gerats T. Plant tolerance to high temperature in a changing environment: scientific fundamentals and production of heat stress-tolerant crops. Front Plant Sci. 2013;4. https://doi.org/10.3389/fpls.2013.00273.

63. Jacob P, Hirt H, Bendahmane A. The heat-shock protein/chaperone network and multiple stress resistance. Plant Biotechnol J. 2017;15:405-14. https:// doi.org/10.1111/pbi.12659.

64. Heckathorn SA, Downs CA, Coleman JS. Small heat shock proteins protect electron transport in chloroplasts and mitochondria during stress. Am Zool. 1999;39:865-76. https://doi.org/10.1093/icb/39.6.865.

65. Downs CA, Coleman JS, Heckathorn SA. The chloroplast 22-Ku heat-shock protein: A lumenal protein that associates with the oxygen evolving complex and protects photosystem II during heat stress. J Plant Physiol. 1999;155:477-87. https://doi.org/10.1016/S0176-1617(99)80042-X.

66. Kim KH, Alam I, Kim YG, Sharmin SA, Lee KW, Lee SH, Lee BH. Overexpression of a chloroplast-localized small heat shock protein OsHSP26 confers enhanced tolerance against oxidative and heat stresses in tall fescue. Biotechnol Lett. 2012;34:371-7. https://doi.org/10.1007/s10529-0110769-3.

67. Liu Y, Wu R, Wan Q, Xie G, Bi Y. Glucose-6-phosphate dehydrogenase plays a pivotal role in nitric oxide-involved defense against oxidative stress under salt stress in red kidney bean roots. Plant Cell Physiol. 2007;48:511-22.

68. Abraham E, Hourton-Cabassa C, Erdei L, Szabados L. Methods for determination of proline in plants. Methods Mol Biol. 2010;639:317-31. https://doi.org/10.1007/978-1-60761-702-0_20.

69. Marx H, Minogue CE, Jayaraman D, Richards AL, Kwiecien NW, Siahpirani AF, Rajasekar S, Maeda J, Garcia K, Del Valle-Echevarria AR, Volkening JD, Westphall MS, Roy S, Sussman MR, Ane JM, Coon JJ. A proteomic atlas of the legume Medicago truncatula and its nitrogen-fixing endosymbiont Sinorhizobium meliloti. Nat Biotechnol. 2016;34:1198-205. https://doi.org/10. 1038/nbt.3681.

70. Pundir S, Martin MJ, O'Donovan C. UniProt protein knowledgebase. Methods Mol Biol. 2017;1558:41-55. https://doi.org/10.1007/978-1-49396783-4_2.

71. Jin J, Tian F, Yang DC, Meng YQ, Kong L, Luo J, Gao G. PlantTFDB 4.0: toward a central hub for transcription factors and regulatory interactions in plants. Nucleic Acids Res. 2017:45:D1040-5. https://doi.org/10.1093/nar/ gkw982.
72. Tian F, Yang D, Meng Y, Jin J, Gao G. PlantRegMap: charting functional regulator maps in plants. Nucleic Acid Res. 2020;48:1104-13.

73. Supek F, Bosnjak M, Skunca N, Smuc T. REVIGO summarizes and visualizes long lists of gene ontology terms. PLoS One. 2011;6(7):e21800.

74. Oliveros, Juan C. "Venny". An interactive tool for comparing lists with Venn Diagrams, 2007. https://bioinfogp.cnb.csic.es/tools/venny/.

\section{Publisher's Note}

Springer Nature remains neutral with regard to jurisdictional claims in published maps and institutional affiliations.

\section{Ready to submit your research? Choose BMC and benefit from:}

- fast, convenient online submission

- thorough peer review by experienced researchers in your field

- rapid publication on acceptance

- support for research data, including large and complex data types

- gold Open Access which fosters wider collaboration and increased citations

- maximum visibility for your research: over $100 \mathrm{M}$ website views per year

At $\mathrm{BMC}$, research is always in progress.

Learn more biomedcentral.com/submissions 